\title{
LA RESPUESTA PENAL INTERNACIONAL FRENTE A LA CORRUPCIÓN. CONSECUENCIAS SOBRE LA LEGISLACIÓN ESPAÑOLA ${ }^{1}$
}

\author{
Ignacio Berdugo Gómez de la Torre
}

Sumario: 1. CONSIDERACIONES GENERALES SOBRE LA CORRUPCIÓN. 2. INSTRUMENTOS INTERNACIONALES CONTRA LA CORRUPCIÓN. 3. LAS REFORMAS DE LA LEGISLACIÓN PENAL ESPAÑOLA. 4. CONCLUSIONES.

\section{CONSIDERACIONES GENERALES SOBRE LA CORRUPCIÓN}

En la actualidad la corrupción constituye un tema de gran transcendencia para la opinión pública, basta con ver en nuestro país los resultados que reco-

${ }^{1}$ Este trabajo se ha realizado en el marco del Proyecto de investigación entre la Universidad de Salamanca y la Universidad de Sao Paulo, sobre «Criminalidad económica y corrupción. Análisis a la luz de las iniciativas internacionales y de los ordenamientos brasileños y español», su contenido es desarrollo y profundización del estudio elaborado por BERDUGO Gómez De LA Torre, I. y LiBeratore S. BecharA, A. E., «O controle da corrupçao: a experiencia a española», Revista dos Tribunais, n 103, Septiembre 2014, pp. 359 a 383.

Hace cinco años realizaba mi primera aproximación al estudio de la respuesta penal frente a la corrupción, desde entonces y hasta hoy, con machacona periodicidad llegan a la opinión pública noticias de nuevos casos de corrupción, de uso del poder, por parte de quien lo detenta en el propio beneficio alejándose del fin público que legitima su ejercicio. Esta situación, a priori, nos indica, al menos, la importancia de la corrupción en nuestra sociedad y la falta de eficacia de las respuestas dadas hasta ahora por el legislador. Lo que, por otro lado, supone una invitación a continuar reflexionando sobre las medidas jurídicas y no jurídicas a afrontar frente a ella y muy especialmente sobre el papel que puede y debe jugar el viejo recurso a los delitos y las penas. BERDUGo GómEz DE LA TORRE, I. y FABIÁN CAPARRós, E., «Corrupción y Derecho Penal: nuevos perfiles, nuevas respuestas», en Revista Brasileira de Ciencias Criminais, $\mathrm{n}^{\circ} 81,2009$, pp. 7 y ss. 
ge el barómetro del CIS o la repercusión que tienen los Informes anuales de Transparencia Internacional.

El barómetro del $\mathrm{CIS}^{2}$ ha reflejado la importancia que, con un notable incremento en los últimos tiempos, damos los españoles a la corrupción. En noviembre de 2013, la corrupción, con un $31,8 \%$, era, tras el paro, con un $77,7 \%$, el problema que más preocupaba a los españoles. Un año después, en noviembre 2014, paro y corrupción continúan siendo para los españoles los dos mayores problemas, pero mientras el paro mantiene su porcentaje en un $77 \%$, la corrupción lo incrementa hasta un $63,8 \%$.

Esta percepción negativa de la corrupción se ha agravado en los últimos tiempos, hecho que también es confirmado por los índices de percepción de la corrupción elaborados por Transparencia Internacional. En el índice de 2006 España ocupaba el puesto 23, con una puntuación de 6,8; en el de 2014 ocupa el puesto 37, con una puntuación de $6,0^{3}$. Ciertamente el último índice exterioriza una cierta consolidación en la percepción de la corrupción, en especial si se compara con los últimos años, lo que, en opinión de Transparencia Internacional, «viene a demostrar que España no tiene corrupción sistémica, como ocurre en un gran número de países, sino múltiples escándalos de corrupción política en los niveles superiores de los partidos y en los gobiernos locales y autonómicos» ${ }^{4}$.

${ }^{2}$ El barómetro que mensualmente, salvo agosto, elabora el Centro de Investigaciones Sociológicas, tiene como objetivo medir determinados aspectos de la opinión pública española. Puede consultarse en su página web, <www.cis.es $>$ (último acceso: 14.5.2015). Estos datos ratifican los resultados de otras encuestas, así, la Comisión Europea en el anexo referido a España de su Informe de lucha contra la corrupción de la UE, p.3, textualmente afirma: «Según el Eurobarómetro especial de 2013 sobre la corrupción, el 63 \% de los encuestados (porcentaje más elevado de la UE) se considera afectado personalmente por la corrupción en su vida cotidiana (media de la UE: $26 \%$ ), en tanto que el $95 \%$ manifiesta que la corrupción es un problema muy extendido en el país (media de la UE: $76 \%$ ) y el $91 \%$ afirma que existe corrupción en las instituciones locales y regionales (media de la UE: 77 \%)». Se peude consultar el informe en $<$ http://ec.europa.eu/dgs/home-affairs/what-we-do/policies/organized-crime-and-human-trafficking/corruption/anticorruption-report/docs/2014_acr_spain_chapter_es.pdf> (último acceso: 14.5.2015).

3 Los índices de Transparencia Internacional pueden consultarse en $<$ www.transparency.org $>$ o en $<$ www.transparencia.org.es $>$ (último acceso: 14.5.2015). Ciertamente el mayor descenso se produjo en 2013, año en el que España retrocedió 10 puestos, con una nota de 5,9; descenso que solo superaron Gambia, Malí y Guatemala.

4 Ver el índice de percepción de la corrupción: La corrupción en el mundo durante 2014 en <www.transparencia.org.es $>$ (último acceso: 14.5.2015). Por otro lado, en España, la percepción de cuáles son las instituciones más corruptas se concentra en los partidos políticos y en el poder legislativo, lo que puede ponerse en conexión con la crisis de legitimación institucional que genera la corrupción. Una elemental reflexión sobre las causas de la corrupción en España, las vincula, históricamente, en la época anterior a la crisis, 
Es indudable que estos datos sobre la valoración negativa que socialmente se da a la corrupción tienen su explicación más próxima en casos tan mediáticos como Gürtel, los ERE, Bárcenas, Pujol o NOOS; este último con imputación incluso de miembros de la familia del rey.

En análogo sentido, en su último informe, Transparencia Internacional aborda la explicación de este descenso en el ranking que España ha experimentado, especialmente en los dos últimos años. Con acierto estima que las razones son complejas pues, "por una parte, los sistemas de control se han mostrado más eficaces y han venido aflorando muy numerosos casos de corrupción; por otra parte, las denuncias de los medios de comunicación y el relevante eco social y atención prestada a los casos ahora aflorados han influido intensamente en la percepción ciudadana, generando un estado general de indignación; también es cierto que la crisis económica ha incrementado el nivel de exigencia social, y aunque la justicia viene cumpliendo su función con cierta eficacia y nivel de resultados, a pesar de su lentitud, se ha generado desde fines de 2009 un muy alto nivel de alarma social; finalmente, aunque el enfriamiento de la economía, especialmente en el sector urbanístico, permite pensar que los casos de corrupción se han reducido en ese ámbito, la lentitud de las sanciones penales, la baja intensidad de las penas en casos de corrupción relevantes, la expansión de los escándalos a las instituciones clave del Estado, y la sensación de impunidad explican bien la percepción social negativa que se mantiene en este Índice» ${ }^{5}$.

La corrupción, pese a que hoy tenga un indudable protagonismo en los medios de comunicación, no es un rasgo de nuestro tiempo, es tan antigua como el propio poder, pues éste siempre ha podido ser utilizado de forma des-

cuando se construía, al urbanismo, y en consecuencia a la política municipal y siempre, antes y ahora, a la financiación de partidos y sindicatos. En este sentido es altamente significativo que el capítulo español de Transparencia Internacional tenga un apartado especial para medir el grado de transparencia de los Ayuntamientos. Aunque como subraya la propia organización, la falta de transparencia no es igual a existencia de corrupción, sino a presencia de una situación que favorece el que se produzca. El índice sobre transparencia en los ayuntamientos que también elabora Transparencia Internacional, ahora de carácter bianual, puede verse en <www.transparencia.org.es>. En 2012 se evaluaron 110 ayuntamientos, de las grandes ciudades, el ayuntamiento más transparente es Bilbao, que obtenía junto a otros siete ayuntamientos la máxima puntuación, mientras que Salamanca ocupa el puesto 84, y la media general era de 70,9 sobre 100. En la evaluación de 2014, hecha pública recientemente, la situación ha experimentado una notable mejora. Junto a Bilbao, otros dieciocho ayuntamientos, Barcelona entre ellos, alcanzan la máxima puntuación. Salamanca también mejora, pasa a ocupar el puesto 54 y la media general alcanza el 85,2 . El último lugar, el ayuntamiento menos transparente, es Granada con una puntuación de 28,8 .

5 El informe puede consultarse en $<$ www.transparencia.org.es $>$ (último acceso: 14.5.2015). 
viada. Lo que ocurre es que, de un lado, las características de la sociedad actual han potenciado sus efectos y de otro, la evolución del Estado y el abandono de la patrimonialización del ejercicio del poder, con el traslado de la soberanía, del origen del poder, al pueblo, han traído consigo la potenciación de sus efectos y la justificación de la criminalización de estos comportamientos.

Las conductas de corrupción han dejado de afectar únicamente al buen funcionamiento de la Administración, al multiplicarse exponencialmente sus efectos económicos y políticos, que pasan a un primer plano, favorecidos por la internacionalización tanto de la economía como de la política y por el desarrollo de las nuevas tecnologías 6

La internacionalización, en especial la de la economía, hace que lo que era únicamente un problema nacional adquiera una complementaria dimensión internacional, favorecida además, por el desarrollo de las nuevas tecnologías, que posibilita nuevas formas de actuación, por la existencia de empresas multinacionales, por la inversión extranjera y por la existencia de los denominados «paraísos fiscales» ${ }^{7}$. Este hecho proporciona una primera explicación a la existencia de regulación internacional de las relaciones económicas acompañada de distintos instrumentos jurídicos ${ }^{8}$, que en el ámbito regional o global pretenden servir de base a una política criminal que aborde con eficacia la lucha contra lo que se ha calificado como «explosión» del contenido de la corrupción al incorporar nuevas formas y nuevos sujetos ${ }^{9}$.

${ }^{6}$ El peso del factor internacional en la corrupción es analizado por PÉREZ CEPEDA, A. y BENITO SÁNCHEZ, D., «La política criminal internacional contra la corrupción», en BERDugo Gómez De La Torre, I. y Liberatore S. Bechara, A. E. (coords.), Estudios sobre la corrupción. Una reflexión hispano brasileña, Centro de Estudios Brasileños, Salamanca 2013, en especial pp. 13 a 21.

${ }^{7}$ La denominación de «paraísos fiscales» se aplica a países o territorios cuya política de opacidad fiscal facilita el blanqueo de capitales fruto de la corrupción o de otros comportamientos delictivos y que proceden de terceros países. La OCDE ha planteado acciones para afrontar estas situaciones. Entre otras, ha publicado una «lista negra» de países que eran considerados como de refugio de dinero procedente de delitos. Se puede ver en la página de la OCDE: <www.oecd.org> último acceso 14.5.2015).

En cualquier caso la definición de que se entiende por «paraíso fiscal» no está exenta de polémica. Entiendo que es clarificadora la descripción que realiza GARZÓN EsPINOSA, A., «Paraísos fiscales en la globalización financiera», en Historia Actual Online, $n^{\circ} 26$, 2011, p.143, «territorios cuyas regulaciones, fundamentalmente fiscales y financieras, son establecidas con el fin de atraer dinero procedente del exterior que no tendrá como destino la actividad productiva del país receptor. Hablamos entonces de paraísos fiscales sólo para extranjeros, ya que para los residentes las regulaciones suelen ser mucho más estrictas».

8 Vid., PÉrez CePeda, A. y Benito SÁnChez, D., «La política criminal internacional contra la corrupción», op. cit., pp. 21 y ss.

9 Berdugo Gómez De La Torre, I. y Fabián Caparrós, E., «Corrupción y Derecho Penal: nuevos perfiles, nuevas respuestas», op. cit., pp. 11 y ss. 
Esta nueva realidad hace que la política criminal frente a la corrupción se torne más compleja, al presentar ésta conductas complementarias encaminadas a favorecer que el corrupto se aproveche de sus beneficios, este sería el caso en especial de los supuestos de lavado de dinero, y al estar vinculada la corrupción en muchas de sus manifestaciones a la criminalidad organizada. Muchas veces, por tanto, estamos ante supuestos de criminalidad transfronteriza, lo que refuerza el rasgo internacional de estos comportamientos.

En la actualidad, la aproximación al hecho de la corrupción se lleva a cabo desde las consecuencias negativas que tiene para una sociedad el ejercicio del poder buscando el propio beneficio. Este paso a un primer plano de sus efectos políticos y económicos trae, como primera consecuencia, que las conductas de corrupción dejen de ser sólo propias de funcionarios, como lo fueron durante mucho tiempo, con lo que se amplía el listado de potenciales sujetos activos, entre otras razones, porque es evidente que no sólo ellos tienen poder. Esto hace que aumente la relación de comportamientos delictivos que puedan ser considerados como vinculados en mayor o menor grado a la corrupción y que se incorporen a ella conductas del ámbito de la denominada «corrupción privada». No hay que olvidar, por tanto, que cuando se habla de «corrupción» no se está empleando un término jurídico, sino criminológico, en cuanto hace referencia a la etiología de un hecho delictivo y que, por otra parte, va más allá del contenido del Código penal.

Reflexionar hoy sobre la corrupción supone hacerlo sobre la delincuencia económica, implica situarse dentro de la criminalidad de cuello blanco, se trata por tanto de comportamientos llevados a cabo por los poderosos, y necesariamente supone tener presente la diferencia entre los procesos de criminalización primaria y secundaria, particularmente acusados en esta delincuencia.

Las implicaciones de la corrupción y por tanto la respuesta frente a la misma superan las fronteras del Derecho penal y, por tanto, puede ser analizada desde un plano económico, político, sociológico, desde su incidencia en las relaciones internacionales o desde distintas perspectivas jurídicas.

El análisis desde una perspectiva político criminal, y en concreto desde la respuesta al interrogante de cómo debe utilizarse el Derecho penal para pretender evitar estos comportamientos o de cuál es la respuesta eficaz frente a los mismos, es un ejemplo paradigmático de los problemas político criminales y dogmáticos que presenta ese campo tan complejo denominado «nuevo Derecho penal $\rangle^{10}$.

${ }^{10}$ Sobre este Derecho Penal, también denominado «moderno Derecho Penal», puede verse en la doctrina española la ya clásica monografía de Silva SÁnchez, J., La expansión del Derecho penal. Aspectos de la politica criminal en las sociedades posindustriales, $2^{\mathrm{a}}$ edic., Madrid 2001, o la de HASSEMER, W. y MuÑoz CONDE, F., La responsabilidad por el producto en Derecho Penal, Tirant lo Blanch, Valencia 1995. 
Es indudable que los rasgos históricos y actuales de cada país condicionan los rasgos de «su» corrupción y como los momentos de mayor inversión económica o en general de mayor intervención del Estado posibilitan un aumento de las conductas de corrupción, que está favorecido en muchos casos por la existencia de una excesiva burocracia.

En este sentido, las situaciones de crisis económica crean una respuesta social de mayor rechazo hacia la corrupción, que, en sus situaciones más extremas, puede llevar a cuestionar el sistema político, a abandonar posiciones, que de hecho han existido, de tolerancia y comprensión frente a la corrupción y a plantear con carácter general una indiscriminada falta de legitimación en quienes detentan el poder político.

La respuesta penal frente a la corrupción es por tanto un auténtico laboratorio para los fines de la pena, especialmente para proporcionar argumentos a los que cuestionamos la prevención general positiva.

La corrupción, por tanto, es hoy un problema político, económico, social y jurídico y también un complejo problema para el Derecho Penal. Todos estos aspectos hacen que la corrupción sea poliédrica en sus manifestaciones y plural en sus consecuencias. El no ignorar esta realidad es condicionante de una lucha eficaz frente a ella y debe conducir a no caer en la simplificación de creer, o de intentar trasmitir, que la lucha contra la corrupción es exclusivamente una cuestión a solventar a través del contenido de los tipos penales. Al contrario, hay que afrontar una política criminal que repose sobre instrumentos preventivos y se funde en otros instrumentos de control social, en la que el Derecho penal tenga la legitimación que le proporciona su carácter subsidiario y fragmentario.Estos datos, las cifras de estos índices, y las cifras totales de casos enjuiciados ${ }^{11}$, permiten extraer, como primera conclusión, el fracaso en España de la política preventiva frente a la corrupción ${ }^{12}$ y la percepción generalizada de los procesos de criminalización secundaria como ineficaces ${ }^{13}$. Lo que a su vez nos lleva a

11 En noviembre de 2014, Europa Press, cifraba en nuestro país en más de 1900 los imputados por casos de corrupción y en 170 los condenados por este motivo. Aunque matizaba que la mayoría de estos no están en prisión por razón de la pena que se les impuso o por estar pendientes de recursos.

${ }_{12}$ En el IPC de 2013, Aspectos más destacados del Índice en <www.transparencia. org.es $>$ (último acceso: 14.5.2015). Transparencia Internacional ya se pronunciaba con contundencia sobre el fracaso de esta política, «la percepción de que se ha perdido una década en la lucha contra la corrupción en España y que el Gobierno no parece decidido a afrontar seriamente el problema. En manos del ejecutivo está cambiar esta tendencia».

${ }_{13}$ En este sentido es particularmente significativa la lectura de las Conclusiones de la $X X V$ reunión nacional de jueces decanos de España, celebrada en Valencia del 1 al 3 de Diciembre de 2014, <www.poderjudicial.es> (último acceso: 14.5.2015). Toman como punto de partida la creación de las condiciones para alcanzar una necesaria «regeneración 
constatar el carácter puramente simbólico de bastantes de las reformas penales llevadas a cabo en este campo, que provocan un efecto boomerang, inherente a muchos cambios legislativos basados en una prevención general positiva, pues en lugar de generar una pretendida confianza en la ley y en el sistema, el cómo de su aplicación, o mejor de su no aplicación, lleva a la conciencia generalizada de la desigualdad ante la ley y a una crisis de la legitimación institucional ${ }^{14}$.

Con carácter general, como ya se ha apuntado, dos son los rasgos de la corrupción que deben tenerse en cuenta para abordar una política criminal eficaz frente a ella. El primero, la dimensión internacional de sus manifestaciones de más gravedad, lo que necesariamente va a exigir la cooperación entre los Estados, plasmada en instrumentos internacionales y en garantizar la aplicación de los mismos.

El segundo, tener presente el carácter poliédrico de sus manifestaciones, la diversidad de sus causas vinculadas a la historia y a la realidad de cada país, y finalmente la potencial gravedad de sus consecuencias. Lo que a su vez nos lleva necesariamente a no limitar la respuesta del Estado al Derecho penal, sino a propugnar políticas mucho más complejas de carácter preventivo, que pasan por la transparencia generalizada y por la utilización de otras ramas del ordenamiento jurídico.

La política criminal frente a la corrupción no puede reducirse al recurso, muchas veces simplemente simbólico al Derecho penal, sino que requiere ante todo una política de transparencia en la gestión pública. Por eso, aunque su promulgación haya tenido un notable retraso, hay que valorar positivamente, la Ley 19/2013, de 9 de diciembre, de transparencia, acceso a la información pública y buen gobierno, pese a que su aplicación efectiva, tras más de un año de vigencia, no esté exenta de trabas y peque de lentitud. Pero, sin duda esta norma y otra serie de disposiciones no necesariamente penales

democrática» de nuestra sociedad. Con razón subrayan, p.13, «lamentablemente se olvida que hay que partir en este punto de una premisa ineludible: sin juzgados eficientes dicha regeneración es imposible».

Para lograr esta eficiencia en la lucha contra la corrupción, los jueces proponen hasta 58 medidas, agrupándolas en los siguientes apartados A) Medidas estructurales, organizativas y de gestión; B)Medidas de refuerzo y apoyo; C) Medidas de reforma del proceso penal en general; D) Medidas relativas al tribunal del jurado; E) Medidas relativas a los aforamientos; F) Medidas relativas a los indultos; G) Ministerio fiscal y policía judicial; H) Medidas relativas a los bienes intervenidos y a las responsabilidades civiles y pecuniarias; I) Medidas relativas a testigos y peritos; J)Medidas relativas a la corrupción en el Código penal; K) Otras medidas contra la corrupción en diferentes ámbitos.

${ }^{14}$ Sobre este punto, por todos, véanse las acertadas páginas que dedica LIBERATORE S.Bechara, A. E., Bem jurídico penal, Quartier Latin, Sao Paulo, 2014, pp. 213 y ss. 
constituyen en España, pasos importantes para consolidar una cultura democrática en la gestión de lo público ${ }^{15}$.

Este punto de partida hace necesario continuar debatiendo el contenido que debe presentar la política criminal frente a los comportamientos de corrupción. Las páginas que siguen pretenden abordar la dimensión internacional de la corrupción, aspecto de la misma que entiendo es de particular importancia en el momento actual por ser la internacionalización un rasgo del actual momento histórico y que se proyecta, sobre la política, sobre la economía, sobre la cultura y, por supuesto también sobre el contenido del Derecho $^{16}$.

\section{INSTRUMENTOS INTERNACIONALES CONTRA LA CORRUPCIÓN ${ }^{17}$}

Una constante en las últimas reformas de la legislación penal española ha sido buscar su justificación en la necesidad de cumplir con las obligaciones derivadas de los Convenios Internacionales suscritos por España en especial las vinculadas a la pertenencia a la Unión Europea ${ }^{18}$. Estas obligaciones efectivamente existen, pero, como recordábamos recientemente ${ }^{19}$, el legislador español las ha cumplimentado con desigual diligencia. Además, en relación con la corrupción, desde un primer momento no hay que olvidar que estas obligaciones no se limitan a modificaciones de la legislación penal.

${ }^{15}$ La lectura del Anexo referido a España del ya citado Informe de la Comisión Europea incide en estos aspectos no penales, incide en especial en aspectos administrativos, de incompatibilidades, de estructura del Estado, haciendo énfasis en la contratación pública y en la necesidad de homogeneizar políticas de control a nivel autonómico y municipal. Vid el texto en $<$ http://ec.europa.eu/dgs/home-affairs/what-we-do/policies/organized-crime-andhuman-trafficking/corruption/anti-corruption-report/docs/2014_acr_spain_chapter es.pdf>, (último acceso: 14.5.2015).

16 Sobre la trascendencia de la internacionalización en el actual Derecho penal, pueden verse las páginas que dedico en Berdugo Gómez De La Torre, I., Viejo y nuevo Derecho Penal. Principios y desafios del Derecho penal de hoy, Iustel, Madrid, 2012, pp. 125 y ss.

${ }_{17}$ Nos referiremos únicamente a los instrumentos internacionales que afectan directamente a España en virtud de su pertenencia a instituciones de este carácter. Asimismo, excluimos abordar aquellos acuerdos bilaterales que haya suscrito España con Estados concretos.

18 A título de ejemplo, la amplia reforma de 2010, de acuerdo con su Exposición de Motivos, responde a «las obligaciones internacionales, especialmente en el ámbito de la armonización jurídica europea», contraídas por España.

19 Berdugo Gómez De La Torre, I. y Liberatore S. Bechara, A. E., «El Proyecto de Código penal español de 2013. Algunas consideraciones político criminales», Revista Penal 34, 2014, p.20. 
Los instrumentos internacionales plantean siempre el problema del control de su cumplimiento por parte de los Estados signatarios. Efectivamente, con carácter general, son abundantes los supuestos en que se refleja la tensión entre la soberanía estatal y las obligaciones derivadas de la aplicación de un Tratado. Esta tensión es aún mayor cuando la materia objeto del Tratado es de carácter penal, por la conexión directa de esta rama del ordenamiento con la soberanía y por la trascendencia que muchas decisiones penales tienen sobre la opinión pública.

Respecto a las fuentes de estos instrumentos internacionales referidos a la corrupción, en el caso de España se centran, en el ámbito global, en Naciones Unidas y en la OCDE, y en el regional, en la Unión Europea y en el Consejo de Europa. De todos ellos, como adelantábamos, se derivan obligaciones de distinto contenido y naturaleza en forma de compromisos o de recomendaciones.

Dentro de los textos internacionales referidos a la corrupción, el más significativo es la Convención contra la corrupción suscrita en Mérida en $2003^{20}$ en el marco de Naciones Unidas. Esta Convención vino precedida por la Convención de Viena de 1988 contra el blanqueo, y por la de Palermo de 2000 , contra la criminalidad organizada. Estas dos últimas, aunque con objetivos más amplios que la corrupción, abordaban dos comportamientos, el blanqueo y la criminalidad organizada, que están presentes o que acompañan a muchas de las manifestaciones más graves de corrupción. En este sentido es claro el Preámbulo de la Convención de Mérida $^{21}$ al recordar, «los vínculos entre la corrupción y otras formas de delincuencia en particular la delincuencia organizada y la delincuencia económica, incluido el blanqueo de dinero».

La existencia de una Convención como la de Mérida que tiene por objeto específico la corrupción, a la que no define, pero que aborda en todos sus aspectos, no sólo los económicos, se justifica, según sus primeras afirmaciones, en «la gravedad de los problemas y las amenazas que plantea la corrupción para la estabilidad y la seguridad de las sociedades al socavar las instituciones y los valores de la democracia, la ética, y la justicia y el comprometer el desarrollo sostenible y el imperio de la ley».

Esta Convención contempla, lo que merece una valoración muy positiva, la práctica totalidad de los problemas que es necesario afrontar para que una

${ }^{20}$ El texto completo de la Convención de Mérida puede consultarse en NACIONES Unidas. Oficina Contra la Droga Y El Delito, Convención de las Naciones Unidas contra la corrupción, Naciones Unidas, Nueva York, 2004.

${ }^{21}$ La Convención de Mérida viene precedida por la Resolución 55/188 de la Asamblea General de Naciones Unidas y por la 55/61 del mismo órgano. Sobre los pasos previos a la Convención de Mérida, vid. Pérez CePeda, A. y Benito Sánchez, D., «La política criminal internacional contra la corrupción», op. cit., p. 23. 
política criminal frente a la corrupción pueda llegar a ser eficaz. Así, recoge, junto a consideraciones generales, objeto de su primer capítulo, y medidas represivas en su capítulo tercero, una amplia relación de medidas preventivas, en su capítulo segundo, un extenso capitulo, el cuarto, referido a la cooperación jurídica internacional y un capítulo final que contempla una importante relación de reglas dedicadas a la recuperación de activos.

Pero la Convención adolece de las dificultades, frecuentes en Naciones Unidas, de no articular mecanismos funcionales para poder impulsar y garantizar el cumplimiento de sus prescripciones ${ }^{22}$. También la heterogeneidad de los Estados miembros lleva a diferenciar dentro de las medidas represivas propuestas, aquellas cuyo contenido es de obligatorio cumplimiento y aquellas que son meras recomendaciones, baste la lectura de la fórmula empleada en varias ocasiones: los Estados signatarios «considerarán la posibilidad de tipificar como delito».

Los aspectos económicos de la corrupción objetivamente actúan como motor último de la internacionalización de la respuesta frente a ella, en especial por sus efectos negativos sobre el comercio internacional o sobre las relaciones entre los Estados. La pretensión de tener una respuesta eficaz frente a éstos ha sido desde hace tiempo un objetivo para la OCDE.

Esta organización, después de un largo proceso ${ }^{23}$, logra elaborar en 1997, un Convenio sobre la lucha contra el soborno de los funcionarios públicos extranjeros en las transacciones internacionales. El Convenio obliga a los Estados signatarios a tipificar como delito en sus ordenamientos nacionales la conducta de quien soborna a un funcionario extranjero «para conseguir o conservar un contrato u otro beneficio irregular en la realización de actividades económicas internacionales» ${ }^{24}$. Por tanto, no obliga a tipificar la conduc-

${ }^{22}$ El mecanismo de examen de la aplicación de la Convención de Naciones Unidas contra la corrupción, establecido por la Resolución 3/1, es por lo menos de dudosa eficacia, al establecer que requiere el acuerdo entre los evaluadores y el país evaluado y tener un carácter confidencial. Vid. PÉRez CePedA, A. y Benito SÁnChez, D., «La política criminal internacional contra la corrupción», op. cit., p. 31.

${ }^{23}$ Benito SÁnchez, D., El delito de corrupción en las transacciones comerciales internacionales, Iustel, Madrid 2012, pp.72 y ss., las primeras actuaciones de la OCDE contra la corrupción se inician en 1976 con la elaboración de unas «Líneas directrices de la OCDE para empresas multinacionales». En todas las actuaciones de esta organización en materia de corrupción tiene un importante papel el Grupo de Trabajo que se crea en su seno y la cooperación que para el seguimiento de sus convenios mantiene con Transparencia Internacional.

${ }^{24}$ El art.1 del Convenio establece, «Cada parte tomará las medidas que sean necesarias para tipificar como delito en su derecho que una persona deliberadamente ofrezca, prometa o conceda cualquier beneficio indebido pecuniario o de otra índole a un agente público extranjero, ya lo haga de forma directa o mediante intermediarios, para su beneficio o para el de un tercero; con la finalidad de que este servidor actúe o se abstenga de 
ta del funcionario, que es una cuestión del Derecho de su país, ni contempla la corrupción entre particulares ${ }^{25}$.

El Convenio, el más importante para abordar la corrupción de funcionario de un tercer país, en terminología de la OCDE, la «corrupción transnacional» ${ }^{26}$, se debe en gran medida a la iniciativa y presión de los Estados Unidos, que en 1977 había promulgado la Foreign Corrupt Practices Act ${ }^{27}$, seguida en 1996 por la Convención Interamericana contra la corrupción, que fue el primer texto internacional que vinculaba a los Estados firmantes en la adopción de medidas contra la corrupción ${ }^{28}$, aunque el grado de cumplimiento de la Convención por parte de los Estados firmantes objetivamente es muy desigual $^{29}$.

hacerlo en relación con el cumplimiento de deberes oficiales, con la finalidad de conseguir o conservar un contrato u otro beneficio irregular en La realización de actividades económicas internacionales». El texto íntegro del Convenio, puede consultarse en <www.oecd. org> (última consulta: 14.5.2015), en el momento de redactar estas líneas, Enero de 2015, el Convenio ha sido suscrito por 41 países, los miembros de la OCDE, más Argentina, Brasil, Bulgaria, Letonia, Rusia, Colombia y Sudáfrica, aunque como enseguida se expondrá, con un muy distinto grado de cumplimiento.

${ }_{25}$ Ver el análisis del contenido de este Convenio que lleva a cabo BENITO SÁNCHEZ, D., El delito de corrupción en las transacciones comerciales internacionales, op. cit., p. 76 y ss.

${ }^{26}$ Denominación que utiliza la OCDE en su reciente informe para referirse a la corrupción definida en el art.1 del Convenio, vid. OCDE, Rapport de l'OCDE sur la corruption transnationale: une analyse de l'infraction de corruption d'agents publics étrangers, Editions OCDE, 2014, expresamente en p. 7. Disponible en <http://www.oecd-ilibrary. org/docserver/download/2814012e.pdf?expires $=1431600155 \& \mathrm{id}=\mathrm{id} \&$ accname=guest\&c hecksum=109C37D231937388D1BEEBD47AF0949F > (último acceso: 15.1.2015).

27 La Foreing Corrupt Practices Act tiene su origen en el escándalo que supuso la constatación de los sobornos que la empresa Lockheed había realizado a funcionarios japoneses para asegurarse la venta de un determinado modelo de avión. Este comportamiento genera en una opinión pública sensibilizada frente a la corrupción, son los años del Watergate, una situación que lleva a la criminalización de estos comportamientos. En contra estuvieron muchas empresas, sectores políticos y otros gobiernos, que entendían que el problema estaba en los países de los sobornados y no en el de los sobornadores. Sobre esta ley, sus causas, contenido y debates, vid. Benito SÁnchez, D., El delito de corrupción en las transacciones comerciales internacionales, op. cit., pp. 54 a 63, tiene mucho interés la información que se proporciona en p. 56 nota 7.

${ }_{28}$ Sobre la Convención Interamericana contra la corrupción, ver la información y análisis de la misma que lleva a cabo BENITO SÁNCHEZ, D., El delito de corrupción en las transacciones comerciales internacionales, op. cit., p. 63 y ss.

${ }^{29}$ En el último informe de Transparencia Internacional sobre el grado de cumplimiento de este Convenio, TransParency InTERnational: Exporting Corruption: 2014 OECD Progress Report (Disponible en <http://issuu.com/transparencyinternational/docs/2014_exportingcorruption_oecdprogre $>$ (último acceso: 14.5.2015), diferencia cuatro grupo de países, el primero los que tienen mayor grado de cumplimiento lo integran cuatro, Estados Unidos, 
La OCDE desde la entrada en vigor del Convenio ha desarrollado y desarrolla un papel muy activo en la lucha contra la corrupción trasnacional ${ }^{30}$, a través de distintos documentos y recomendaciones, de la colaboración con los países del G20 $0^{31}$, del seguimiento activo del cumplimiento del Convenio y de la constitución de un muy activo grupo de trabajo ${ }^{32}$.

La OCDE, de forma paralela ha continuado con su lucha contra los denominados «paraísos fiscales», países y territorios que por sus políticas bancarias y por su opacidad fiscal juegan un papel decisivo en el lavado de capitales, complemento necesario para muchos de los casos más graves de corrupción ${ }^{33}$. En este punto, la actuación de la OCDE se ve favorecida por la naturaleza global de la reciente crisis económica y por la política que en igual dirección han seguido los países del G20.

El punto de partida de la OCDE ha sido la elaboración de la más conocida lista de Estados considerados como paraísos fiscales, lista que a lo largo de

Alemania, Reino Unido y Suiza, que suponen el 23,1\% de las exportaciones en el mundo; el segundo, está formado por cinco países con moderado cumplimiento, lo integran, Italia, Canadá, Australia, Austria y Finlandia, suponen el 8,3\% de las exportaciones mundiales; el tercer grupo, lo forman ocho países con limitado cumplimiento, está formado por Francia, Suecia, Noruega, Hungría, Sudáfrica, Argentina, Portugal y Nueva Zelanda, que suponen el $7,6 \%$ de las exportaciones mundiales y finalmente un amplio cuarto grupo de veintidós países, Japón, Holanda, Corea del Sur, Rusia, España, Bélgica, México, Brasil, Irlanda, Polonia, Turquía, Dinamarca, República Checa, Luxemburgo, Chile, Israel, Eslovaquia, Colombia, Grecia, Eslovenia, Bulgaria y Estonia, que suponen el 27\% de las exportaciones mundiales.

${ }^{30}$ Lo subraya y da información sobre las distintas recomendaciones BENITO SÁNCHEZ, D., El delito de corrupción en las transacciones comerciales internacionales, op. cit., pp.84-85. Puede consultarse OCDE: Convención para combatir el cohecho de servidores públicos extranjeros en transacciones comerciales internacionales y Documentos relacionados, 2010, en <www.oecd.org/corruption> (acceso el 12.1.2015).

${ }^{31}$ Desde 2010 el G20 ha adoptado en sus sucesivas cumbre un papel activo en la lucha contra la corrupción, mediante la constitución de un Grupo de Trabajo que he diseñado ya un plan de actuación para 2015-2016. Puede consultarse en $<$ https://g20.org/.../ G20_anti_corruption_working_gr> (último acceso: 28.1.2015).

${ }^{\overline{32}}$ La última aportación en Diciembre de 2014 es, OCDE, Rapport de l'OCDE sur la corruption transnationale..., op. cit., en el que analiza 427 casos de corrupción. El estudio tiene un elevado interés, aborda muy distintos aspectos de cómo se lleva a cabo la relación de corrupción, funciones que desarrollan los implicados, sectores económicos en que se produce la corrupción, naturaleza y valor de los sobornos etc. A destacar que el análisis de los casos, pone de relieve que, en contra de los que puede pensarse, son frecuentes los casos de corrupción en los que las dos partes implicadas son de países con un elevado índice de desarrollo (p.35). En concreto, de los 427 casos analizados, en dos tercios los sobornos han ido dirigidos a agentes públicos de países desarrollados, (p.31, ver gráficos 17 y 18).

33 Vid. Saura García, P., «Paraísos fiscales y corrupción», Temas para el debate, $\mathrm{n}^{\mathrm{o}}$ 223 (junio), 2013. FABIÁn CAPARRós, E., El delito de blanqueo de capitales, Colex, Madrid, 1998, en especial pp. 88 y ss. 
los años ha pasado de «negra» a «gris» ${ }^{34}$ y en la que se ha avanzado como instrumento para limitar el secreto bancario y reforzar las relaciones económicas entre los Estados y favorecer sus políticas fiscales nacionales ${ }^{35}$. Pero, aún queda camino por recorrer, pues no hay que olvidar que bastantes de ellos, dado su grado de dependencia, son un claro ejemplo de la doble moral de las grandes potencias económicas. Incluso se puede tener en cuenta el ejemplo de uno de los más importantes casos de corrupción españoles, en los que, la laxa legislación mercantil de algún Estado estadounidense ha sido utilizada como medio para posibilitar un soporte jurídico a complejas operaciones de corrupción ${ }^{36}$.

Dentro de las instituciones europeas, el antiguo Mercado Común, hoy Unión Europea, centra sus disposiciones contra la corrupción prácticamente

${ }^{34}$ A final de la última década del pasado siglo, la OCDE asume como objetivo la actuación contra los paraísos fiscales y señala una lista de 41 países y 21 territorios que le merecían esta consideración. La crisis económica y la presión del G20 hizo que los países de la lista original fuera disminuyendo, entre otras razones por que era relativamente fácil abandonar la lista, bastaba con suscribir 12 convenios bilaterales, donde se comprometían a intercambiar información fiscal y podía ser además entre países que se encontraban en la lista. Sobre este punto véase, GARZÓN EsPINOSA, A., «Paraísos fiscales en la globalización financiera», op. cit., p. 144. El último test de transparencia de la OCDE no ha sido superado por, Brunei, Dominica, Micronesia, Guatemala, Líbano, Liberia, Islas Marshall, Nauru, Panamá, Trinidad y Tobago, Vanuatu.

${ }^{35}$ Cada Estado puede tener su propia lista de «paraísos fiscales», con consecuencias sobre las relaciones económicas con los mismos. En España la lista de los 48 Estados y territorios, que merecen esa consideración, aparece recogida en el RD.1080/1991, de 27 de mayo. El Ministerio de Hacienda en la última actualización de esta lista de diciembre de 2014, reduce la lista a los 33 Estados y territorios, que a continuación se relacionan 1. Emirato del Estado de Bahrein, 2. Sultanato de Brunei, 3 Gibraltar, 4. Anguilla, 5. Antigua y Barbuda, 6. Bermuda, 7. Islas Caimanes, 8. Islas Cook, 9. República de Dominica, 10. Granada, 11. Fiji, 12. Islas de Guernesey y de Jersey (Islas del Canal), 13. Islas Malvinas, 14. Isla de Man, 15. Islas Marianas, 16. Mauricio, 17. Montserrat, 18. República de Naurú, 19. Islas Salomón, 20. San Vicente y las Granadinas, 21. Santa Lucía, 22. Islas Turks y Caicos, 23. República de Vanuatu, 24. Islas Vírgenes Británicas, 25. Islas Vírgenes de Estados Unidos de América, 26. Reino Hachemita de Jordania, 27. República Libanesa, 28 República de Liberia, 29. Principado de Liechtenstein, 30. Macao, 31. Principado de Mónaco, 32. Sultanato de Omán, 33. República de Seychelles.

${ }^{36}$ La sentencia del conocido como caso «ballena blanca», STS 974/2012 de 5.12.2012, en sus hechos probados recoge como, «Por lo general, la persona jurídica extranjera era una sociedad constituida en el Estado norteamericano de Delaware cuya legislación permite que los últimos beneficiarios y dueños de la inversión no aparezcan en la escritura o título constitutivo». Hernández Vigueras, J., "Crisis financiera, rescates bancarios y paraísos fiscales», en El viejo topo, $\mathrm{n}^{\circ} 253,2009$, p.56, no duda en calificar a este Estado como «el paraíso fiscal que no figura en la lista de la OCDE». 
sólo en la dimensión económica de ésta ${ }^{37}$, mientras que el Consejo de Europa sigue una vía de propuestas de mayor amplitud.

Las medidas propugnadas por la Unión Europea contra la corrupción comienzan a adoptarse en los últimos años del pasado siglo y pueden ser situadas dentro de lo que en principio constituye el contenido de un «Derecho penal europeo» ${ }^{38}$, teniendo como objeto la protección de los intereses financieros de la Unión y la delincuencia transfronteriza, rasgos ambos que suelen estar presentes en las conductas de corrupción.

Los primeros pronunciamientos de la Unión Europea en este campo tienen por finalidad afrontar la posible corrupción de los funcionarios comunitarios para garantizar la protección de sus intereses financieros ${ }^{39}$. Este es el sentido de los dos primeros convenios, de 1996 y 1997, pretenden que las legislaciones penales de los Estados miembros tipifiquen como delito «actos de corrupción en los que estén implicados funcionarios de las Comunidades europeas o de los Estados miembros de la Unión Europea $»^{40}$. Estos Convenios fueron completados por el Plan de Acción contra la delincuencia organizada de 1997, dada la conexión de la corrupción con esta forma de delincuencia ${ }^{41}$.

Junto a este camino la Unión Europea ha propugnado el castigo de la corrupción privada para garantizar la libre competencia, aquí la dimensión de

${ }^{37}$ La Comisión Europea en su Informe de la Comisión al Consejo y al Parlamento Europeo. Informe sobre la lucha contra la corrupción en la UE, Bruselas 2014, p.3, expone que el coste de la corrupción para la economía de la UE asciende a 120.000 millones de euros al año. Vid. Texto en <http://ec.europa.eu/dgs/home-affairs/e-library/documents/policies/organized-crime-and-human-trafficking/corruption/docs/acr_2014_ es.pdf> (último acceso: 14.5.2015).

${ }^{38}$ Sobre la Unión Europea y Derecho penal puede consultarse la síntesis que efectuamos en Berdugo Berdugo Gómez De La Torre, I., Viejo y nuevo Derecho Penal. Principios y desafios del Derecho penal de hoy, op. cit., p. 147 y ss. También, ArRoYo ZAPATERo, L.A. y Nieto Martin, A., Fraude y corrupción en el Derecho penal económico europeo. Eurodelitos de corrupción y fraude, Universidad de Castilla la Mancha, Cuenca, 2006.

39 Sobre las primeras iniciativas de la Unión Europea en este campo, véase BENITO SÁNCHEZ, D., El delito de corrupción en las transacciones comerciales internacionales, op. cit, p. 86. Con carácter general sobre la Unión Europea y la corrupción, vid., CARRERA HERNÁNDEZ, F. J., «La persecución penal de la corrupción en la Unión Europea», en AA.VV., Cooperación jurídica internacional, BOE, Madrid, 2001, p. 212.

40 Este es el título del Convenio de 1997 que continúa la línea iniciada el año anterior por el Primer Protocolo Adicional al Convenio relativo a la protección de los intereses financieros de las Comunidades Europeas. Tiene que resaltarse la tardanza en la entrada en vigor de estos Convenios el de 1996 lo hizo el 17 de octubre de 2002 y el de 1997, el 28 de septiembre de 2005, ocho años después de su adopción.

${ }^{41}$ Sobre este plan vid. BENITO SÁnCHEZ, D., El delito de corrupción en las transacciones comerciales internacionales, op. cit., p. 93. 
las consecuencias económicas de la corrupción constituye la clave para el recurso al Derecho penal, que aparece prescrito por la Decisión Marco del Consejo Europeo de 22 de Julio de 2003 relativa a la lucha contra la corrupción en el sector privado ${ }^{42}$, que había sido precedida en 1998 por una Acción común sobre la corrupción en el sector privado. El art. 4 de la Decisión Marco establece de forma taxativa el uso del Derecho penal en estos casos de corrupción ${ }^{43}$ y en los dos artículos siguientes establece la adopción de medidas penales o administrativas frente a los comportamientos de corrupción llevados a cabo por personas jurídicas. Ante la tardanza de los Estados en aplicar el contenido de esta Convención, la Comisión pretendió potenciar su lucha contra la corrupción a través de una Comunicación, en 2003, titulada, «Una política global de la Unión Europea contra la corrupción» ${ }^{44}$.

El Tratado de Lisboa, en la compleja historia de la Unión Europea, abre la puerta a un nuevo contexto político y jurídico, que puede alcanzar nuevos contenidos de carácter penal ${ }^{45}$, pero es claro que independientemente de la incorporación de nuevos contenidos, el Derecho penal fundado en la normativa europea mantiene como objetivo la tutela de los intereses financieros de la Unión y la delincuencia transfronteriza ${ }^{46}$, ámbitos en los que como ya se

${ }^{42}$ Sobre antecedentes, contenido y problemas que plantea puede verse BERDUGo GóMez De LA Torre, I. y CerinA, G., «Sobre la corrupción entre particulares. Convenios internacionales y Derecho comparado», Revista Brasileira de Ciencias Criminais, $\mathrm{n}^{\circ} 89$, 2011 , p. 159 y ss.

${ }_{43}$ El artículo 4 de esta Decisión marco obliga a los Estados miembros a tomar las medidas necesarias para asegurar que los actos de corrupción activa y pasiva en el sector privado sean punibles con sanciones penales efectivas, proporcionadas y disuasorias, $\mathrm{y}$ que incluyan una pena privativa de libertad de una duración máxima al menos de uno a tres años.

$44<$ http://portal.uclm.es/descargas/idp_docs/normativas/politica $\% 20$ global $\% 20$ de $\% 201 \mathrm{a} \% 20$ ue $\% 20$ contra $\% 201 \mathrm{l} \% 20$ corrupcion.pdf> (último acceso: 14.5.2015), recoge el texto de esta Comunicación, (acceso 14.2015). Su contenido es una invitación imperativa a los Estados miembros a que adopten políticas activas de lucha contra conjunta contra la corrupción.

45 Vid. Acale Sánchez, M., «Derecho penal y Tratado de Lisboa», Revista de Derecho comunitario, $\mathrm{n}^{\mathrm{o}} 30,2008$, pp. 359 y ss.

${ }^{46}$ El Tratado de Funcionamiento de la Unión Europea, determina las bases para una competencia penal de la Unión Europea dentro de los denominados eurodelitos. El art.83.1 establece: «El Parlamento Europeo y el Consejo podrán establecer, mediante directivas adoptadas con arreglo al procedimiento legislativo ordinario, normas mínimas relativas a la definición de las infracciones penales y de las sanciones en ámbitos delictivos que sean de especial gravedad y tengan una dimensión transfronteriza derivada del carácter o de las repercusiones de dichas infracciones o de una necesidad particular de combatirlas según criterios comunes. Estos ámbitos delictivos son los siguientes: el terrorismo, la trata de seres humanos y la explotación sexual de mujeres y niños, el tráfico ilícito de drogas, el tráfico ilícito de armas, el blanqueo de capitales, la corrupción, la falsi- 
adelantaba, existe muy frecuentemente una directa conexión con casos de corrupción ${ }^{47}$.

Respecto a la Unión Europea es importante subrayar que, independientemente de sus crisis y de sus tensiones internas, el contenido de las decisiones jurídicas que de ella emanan tienen una obligatoriedad para los Estados superior a la de otras organizaciones internacionales al ser mucho mayor el vínculo entre los Estados miembros.

Por su parte, el Consejo de Europa, creado con el objetivo de defender los Derechos Humanos, el Estado de Derecho y la democracia, a partir de la Conferencia de Ministros celebrado en 1994 en Malta, inicia la adopción de medidas contra la corrupción ${ }^{48}$. El Consejo adopta una posición más amplia al justificar sus propuestas contra la corrupción. Así en el Preámbulo de la Convención penal contra la corrupción, de $1999^{49}$, ratificada por España en 2005 y en vigor a partir de 2010, se afirma que la corrupción, «constituye una amenaza para la primacía del derecho, la democracia y los derechos humanos, que la misma socaba los principios de una buena administración, de la equidad y de la justicia social, que falsea la competencia, obstaculiza el desarrollo económico y pone en peligro la estabilidad de las instituciones democráticas y los fundamentos morales de la sociedad».

Las medidas propuestas por el Consejo arrancan de su «Programa de Acción contra la corrupción» que adoptó en 1996. Al año siguiente el Consejo de Ministros aprobó el 6.11.1997, «Veinte principios directivos para la lucha contra la corrupción». El año 2000 el Consejo de Ministros adopta una recomendación estableciendo un «Código de conducta de los funcionarios públicos» y en 2003 otra Recomendación para el establecimiento de una «Reglas

ficación de medios de pago, la delincuencia informática y la delincuencia organizada». Más adelante en el art. 325.2 establece que «Los Estados miembros adoptarán para combatir el fraude que afecte a los intereses financieros de la Unión las mismas medidas que para combatir el fraude que afecte a sus propios intereses financieros».

${ }^{47}$ Un buen ejemplo es la reciente Directiva 2014/42/UE del Parlamento Europeo y del Consejo de 3 de abril de 2014 sobre el embargo y el decomiso de los instrumentos y del producto del delito en la Unión Europea. Puede consultarse en $<$ http://www.boe.es/ doue/2014/127/L00039-00050.pdf> (último acceso: 14.5.2015).

48 Vid. Benito SÁnCHEZ, D., El delito de corrupción en las transacciones comerciales internacionales, op. cit., pp. 100 y ss.

${ }^{49}$ La Convención penal de 1999, requería para su entrada en vigor, 14 ratificaciones que se obtienen el 1.7.2002. España firma en 2005, ratifica en 2009 y entra en vigor el 28.4.2010. En la actualidad la Convención tiene 45 ratificaciones de países miembros y no miembros del Consejo de Europa y 5 firmas aún no seguidas de ratificación. La Convención es completada por un Protocolo de 2003, en vigor desde 2005. España la ratificó en 2009, entrando en vigor el 17.1.2011. En la actualidad ha sido firmado y ratificado por 37 países y está firmado y pendiente de ratificación en otros 9. Ver la información sobre la Convención y sobre el Protocolo, en <www.coe.int/greco> (último acceso: 14.5.2015). 
comunes contra la corrupción en la financiación de los partidos políticos y las campañas electorales $)^{50}$.

El instrumento clave del Consejo de Europa lo constituye la mencionada Convención penal que contempla la incorporación a la legislación penal de los Estados firmantes de una serie de delitos referidos a la corrupción. Su contenido es mucho más amplio que otros instrumentos internacionales, pues aborda el cohecho tanto en el ámbito público, como en el privado y en el internacional y en los tres supuestos, tanto el activo como el pasivo. Además incorpora la responsabilidad penal de las personas jurídicas y una muy amplia serie de medidas procesales y preventivas. La Convención penal está completada por otra de carácter civil del mismo año, también vigente en España a partir de 2010, que recoge el deber de los estados de indemnizar a las víctimas de la corrupción ${ }^{51}$.

El Consejo de Europa, para el seguimiento de la aplicación por los Estados de su política contra la corrupción, creó en 1998 el Grupo de Estados contra la Corrupción $\left(\mathrm{GRECO}^{52}\right)$, del que forma parte España y que periódicamente emite, en diálogo con las autoridades de cada país, informes sectoriales sobre las medidas seguidas por los Estados en su lucha contra la corrupción, con evaluaciones y recomendaciones, de cuyo cumplimiento se hace un ulterior seguimiento ${ }^{53}$.

En enero de 2014, la Comisión hizo público su Informe sobre la lucha contra la corrupción, que dirige al Consejo y al Parlamento ${ }^{54}$. En junio de 2011, la Comisión había adoptado una Comunicación de la Comisión al Par-

${ }^{50} \mathrm{El}$ texto de todos estos documentos puede consultarse en $<\mathrm{http}$ ://europa.eu/abouteu/institutions-bodies/european-council/index_es.htm> (último acceso: 14.5.2015).

${ }^{51}$ La Convención civil de 1999, requería para su entrada en vigor, 14 ratificaciones que se obtienen el 1.11.2003. España la firma en 2005, la ratifica en 2009 y entra en vigor el 1.4.2010. En la actualidad la Convención tiene 35 ratificaciones de países miembros y no miembros del Consejo de Europa y 7 firmas aún no seguida de ratificación.

52 Sobre GRECO, puede consultarse la amplia información contenida en su página web, <www.coe.int/greco> (último acceso: 14.5.2015).

${ }^{53}$ La cuarta ronda de evaluación de las medidas contra la corrupción se he centrado en la «Prevención de la corrupción respecto de parlamentarios, jueces y fiscales», el informe sobre España es público desde el 15.1.2014. Las tres anteriores rondas trataron, la primera sobre la situación general de la corrupción y la lucha contra ella en España, la segunda abordó tres temas, «Los productos de la corrupción. Administraciones públicas y corrupción y Personas Jurídicas y corrupción» y la tercera sobre «Transparencia de la financiación de los partidos políticos». A los documentos de las cuatro evaluaciones sobre España y sobre los demás países se puede acceder a las mismas en <www.coe.int/greco $>$ (último acceso: 14.5.2015).

${ }^{54}$ Comisión Europea, Informe de la Comisión al Consejo y al Parlamento Europeo. Informe sobre la lucha contra la corrupción en la UE. Bruselas 2014. El texto completo puede verse en: <ec.europa.eu/dgs/home-affairs/e-library> (último acceso: 14.5.2015). 
lamento europeo, al Consejo y al Comité Económico y Social europeo ${ }^{55}$ en la que establecía la elaboración de este Informe, que tendrá carácter bianual.

La Comunicación entendía necesaria la realización de este Informe al afirmar que, «la aplicación del marco jurídico de lucha contra la corrupción sigue siendo desigual de un Estado miembro a otro y, en general, no es satisfactoria. No todos los Estados miembros han transpuesto la legislación de la UE contra la corrupción», lo que en opinión de los autores de la Comunicación refleja una falta de compromiso político por parte de algunos Estados miembros. Por tanto, contribuir a paliar esta situación es el objetivo principal del Informe ${ }^{56}$.

Pero la existencia de una «corrupción nacional», que responde a los rasgos propios de cada país, tanto históricos, como políticos, económicos o culturales, lleva a los autores del informe a sostener que: «Una respuesta política eficaz no puede consistir en una serie de medidas estereotipadas; no existe una solución universal. Por ello, el informe examina la corrupción en el contexto nacional de cada Estado miembro, y sugiere cómo se pueden tratar en ese contexto las cuestiones más pertinentes para cada Estado miembro $\rangle^{57}$.

El Informe, por otra parte, se construye en gran medida sobre los análisis y propuestas efectuadas por otras instancias internacionales, en especial la OCDE y el Consejo de Europa a través del GRECO.

El contenido de este Informe tiene un especial interés pues, además de constituir una importante fuente de información sobre la corrupción y las medidas frente a ella en los países miembros de la Unión Europea, en su análisis conjunto, lo que denomina «Capitulo horizontal», procede a una exposición de los puntos críticos y de las mejores prácticas para abordarlos en el conjunto de los países estudiados ${ }^{58}$. El Informe también examina de forma

${ }^{55}$ Comisión Europea, Comunicación de la Comisión al Parlamento Europeo, al Consejo y al Comité Económico y Social Europeo, Bruselas 2011. El texto completo aparece en distintas direcciones electrónicas, se ha utilizado, $<$ http://eurored.ccoo.es/eurored/Instituciones_UE:Comision_Europea>_último acceso: 14.5.2015).

${ }_{56}$ Ibidem, p. 7, «Habida cuenta de las limitaciones que presentan los mecanismos internacionales de vigilancia y evaluación existentes expuestas más arriba, es necesario establecer un mecanismo de control y evaluación específico de la UE, el Informe Anticorupción, a fin de reforzar la voluntad política de los Estados miembros y favorecer la aplicación de los instrumentos legales e institucionales existentes. Este mecanismo deberá combinarse con la participación de la UE en el GRECO».

57 Ibidem, p. 3.

${ }^{58}$ Ibídem, p.8 y ss., la lectura de este capítulo III, en cuatro apartados, A. Dimensión política, B. Mecanismos de control y prevención, C. Represión y D. Zonas de riesgo, analiza comparativamente la situación de la corrupción en los países de la Unión. Importa subrayar que significativamente la referencia al Derecho penal es una más y que puede afirmarse que es un capitulo ya cumplido, p.14, «El Derecho penal contra la corrupción está implantado en general y cumple las normas del Consejo de Europa, las Naciones Unidas y la legislación de la UE». El informe subraya carencias en otros ámbitos, a título 
monográfica la «Contratación pública,» tema central al converger en ella legislaciones nacionales y la normativa de la Unión ${ }^{59}$.

Dentro de este Informe, para este estudio tiene particular interés el anexo referido a España, ${ }^{60}$ que aplica igual esquema que el Informe general. La lectura del mismo pone de relieve como el éxito de la lucha contra la corrupción en España depende, más que de nuevas reformas penales, de su aplicación o de reformas en otros ámbitos que doten de eficacia a la política criminal contra la corrupción.

En su diagnóstico, considera como cuestiones que están en el punto de mira en nuestro país, la financiación de los partidos políticos, la corrupción a nivel regional y local, el conflicto de intereses y la publicidad del patrimonio, el desarrollo urbano ${ }^{61}$, la contratación pública ${ }^{62}$ y la transparencia y acceso a la información.

Los autores del Informe subrayan las reformas ya llevadas a cabo, e incluso consideran algunas buenas prácticas, en la contratación pública a nivel

ejemplo, p.17, respecto al proceso se afirma, «Cabe señalar que las carencias procesales pueden obstaculizar a menudo la investigación de los casos de corrupción en determinados Estados miembros. Ejemplo de ello son las disposiciones poco claras o excesivas del levantamiento de la inmunidad, o su aplicación incorrecta, y las limitaciones que impiden la finalización de los casos complejos, en particular en combinación con largos procedimientos o normas inflexibles sobre el acceso a la información bancaria que obstaculizan las investigaciones financieras y la cooperación transfronteriza».

El Informe señala como sectores más vulnerables a la corrupción, p.18 y ss., el desarrollo urbanístico, la planificación medioambiental, la sanidad y la administración fiscal. El capítulo se cierra, p.21, señalando como cuestiones de fondo en las que la política que se siga puede tener efectos sobre la corrupción, en concreto, la política de transparencia y libertad de información, la protección de los denunciantes y la transparencia de la actividad de los grupos de presión.

${ }^{59}$ Comisión Europea, Informe de la Comisión al Consejo y al Parlamento Europeo. Informe sobre la luch a contra la corrupción en la UE, p. 23 y ss. Considera con razón que la contratación pública es un ámbito particularmente expuesto a la corrupción, lo que demanda dado su peso económico una especial atención, máxime cuando, p.26, según el Eurobarómetro de 2013, el 32\% de las empresas de los Estados miembros que participaron en procedimientos de contratación pública, entienden que la corrupción les impidió ganar el contrato.

${ }^{60} \mathrm{El}$ texto de este Informe sobre la situación de la lucha contra la corrupción en España, al que ya nos hemos referido, puede verse en $<$ http://ec.europa.eu/dgs/homeaffairs/what-we-do/policies/organized-crime-and-human-trafficking/corruption/anti-corruption-report/docs/2014_acr_spain_chapter_es.pdf $>$.

${ }^{61}$ Sobre este punto véase OlaizAOLA NoGAles, I. y otros, Corrupción y urbanismo, Universidad de Deusto, Bilbao, 2008.

${ }^{62}$ Sobre la corrupción dentro de la contratación pública puede consultarse por todos JAREÑO LEAL, A., «La corrupción en la contratación pública», en JAREÑo LEAL, A. (Dir.), Corrupción pública: cuestiones de política criminal, Iustel, Madrid, 2014, pp. 149 y ss. 
local ${ }^{63}$ y en la transparencia y en el acceso a la información y la señalada mejora en los índices de transparencia en la Administración municipal. Pero enumeran cuatro aspectos en los que se requiere profundizar, en concreto: seguir trabajando en la normativa de la financiación de los partidos políti$\cos ^{64}$; desarrollar estrategias a la medida para las administraciones regional y local; desarrollar códigos de conducta para los cargos electos a nivel central, regional y local ${ }^{65}$; finalmente, en la contratación pública, tener en cuenta las conclusiones del Tribunal de cuentas y organismos análogos.

De todos los Tratados, Convenios e Informes que se han abordado puede extraerse el denominador común de la existencia, para poder afrontar con eficacia la lucha contra la corrupción, de un importante y largo camino a recorrer fuera del Derecho penal. A veces se trata de puertas que han sido abiertas por reformas penales, un buen ejemplo, al que más adelante me referiré, es trasladar la compliance, que está detrás de la admisión de la responsabilidad de las personas jurídicas, a la prevención de la corrupción en las Administraciones públicas y los partidos políticos como public compliance ${ }^{66}$.

\section{LAS REFORMAS DE LA LEGISLACIÓN PENAL ESPAÑOLA}

El código penal de 1995 desde su entrada en vigor ha sido objeto de sucesivas y reiteradas reformas de distinta importancia ${ }^{67}$, varias de ellas han inci-

${ }^{63}$ COMISIÓN EuROPEA, Informe sobre la situación de la lucha contra la corrupción en España, op. cit., p.14, pone como ejemplo de buena práctica, «la creación de la Oficina de Supervisión y Evaluación de la Contratación Pública en Cataluña o de la Comisión Consultiva para la Transparencia en las Islas Baleares, adscrita a la Consejería de Presidencia, ha fijado estándares de transparencia más estrictos, centralizado la recopilación de datos y mejorado el escrutinio de los procedimientos de contratación pública».

${ }^{64}$ Sobre este punto es consulta imprescindible la reciente monografía de OlaIzola Nogales, I., La financiación ilegal de los partidos politicos: Un foco de corrupción, Tirant Lo Blanch, Valencia 2014.

${ }^{65}$ COMISIÓN EuROPEA, Informe sobre la situación de la lucha contra la corrupción en España, p. 16, donde valora como importante, «garantizar el necesario marco de aplicación de la nueva Ley de transparencia, acceso a la información pública y buen gobierno, incluido un mecanismo de supervisión independiente de la mano de un sistema de sanciones disuasorias»).

${ }^{66}$ De muy elevado interés son los estudios recogidos en el volumen dirigido por NIEto Martín, A. y Maroto Calatayud, M., Public compliance. Prevención de la corrupción en administraciones públicas y partidos politicos, Universidad de Castilla la Mancha, Cuenca 2014.

${ }^{67}$ Berdugo Gómez De La Torre, I. y Liberatore S. Bechara, A. E., «El Proyecto de Código penal español de 2013. Algunas consideraciones político criminales», op . cit., p. 20, nos referimos a como la reiterada referencia a cambios en la realidad social y a las 
dido sobre figuras delictivas que en mayor o menor grado se refieren a conductas que pueden quedar englobadas dentro de la corrupción.

Los Códigos del XIX respondían frente al uso desviado del poder con la tipificación de conductas realizadas por funcionarios y que incidían negativamente sobre el funcionamiento de la Administración. Se trataba por tanto de una corrupción «nacional» que se afrontaba a través de las clásicas figuras del cohecho y la malversación.

La explosión de la corrupción, que se ha sintetizado en las páginas iniciales de este trabajo y que entre otras manifestaciones se materializa en la internacionalización de la corrupción, unida a la presencia de instituciones políticas de carácter internacional o regional, hace necesaria, si se pretende lograr una respuesta eficaz frente a la corrupción, una revisión de estas viejas figuras y la incorporación de otras nuevas, tal como por otra parte, se deriva de la mayor parte de los distintos textos internacionales que hasta ahora hemos expuesto. Una consideración conjunta de sus contenidos permite agrupar sus mandatos y recomendaciones, todas ellas tomando como punto de partida las consecuencias que la corrupción, sea nacional o internacional, tiene en la actualidad.

Un primer grupo de contenidos aborda lo que en puridad se puede denominar corrupción internacional, con distintos contenidos, por un lado la necesidad de que los ordenamientos jurídicos nacionales recojan comportamientos realizados por funcionarios de las distintas instituciones internacionales, en este sentido es clara toda la normativa generada por la Unión Europea y la propia Convención de Mérida.

Por otro y a veces vinculada a este tipo de comportamientos se encuentra la necesidad de afrontar la corrupción de funcionario extranjero, con la finalidad de garantizar las relaciones económicas internacionales. En este campo y como se ha expuesto, es determinante la actuación de la OCDE.

Un segundo grupo de propuestas y recomendaciones va dirigida a abordar las causas concretas de la corrupción en un país concreto, pues finalmente la corrupción nacional puede tener consecuencias internacionales directas, por ejemplo, a través del lavado de dinero al que en seguida me referiré, o indirectas pues la corrupción de un país afecta en mayor o menor medida a los restantes países con los que tiene relaciones, según sea la intensidad de las mismas y ya sean estos vínculos de carácter político o económico.

En este grupo hay que incluir las reformas legislativas referidas a la contratación pública, a la corrupción de particulares, a la financiación de partidos políticos, a la ordenación del territorio o al medio ambiente, o la pretensión de tipificar autónomamente el enriquecimiento ilícito.

obligaciones derivadas de Convenios internacionales «han servido al legislador penal de coartada para llevar a cabo reformas que nada tienen que ver ni con lo uno ni con lo otro». 
Otro grupo de reformas se refieren a comportamientos que no siempre están vinculados a la corrupción, pero que pueden estar vinculados a la significación económica, pues posibilitan beneficiarse de sus efectos. Este es el caso del lavado de dinero y como complemento necesario del mismo las actuaciones, sobre los paraísos fiscales o las dirigidas a la recuperación de activos, que no tienen carácter penal, por lo que no serán abordadas en estudio.

Finalmente, hay que apuntar algunas reformas de parte general que se proyectan también sobre delitos, que implican o presuponen una conducta de corrupción, ya que facilitan su comisión, este es el caso de la responsabilidad de las personas jurídicas, o, como en el caso de la regulación del decomiso, buscan dar un respuesta a sus consecuencias económicas.

El objeto de las páginas que siguen es analizar con brevedad las reformas, algunas muy recientes, que en el Código penal español se vinculan a estos contenidos que a su vez se basan en instrumentos jurídicos internacionales.

En relación al cohecho, el denominador común de los convenios internacionales referidos a la corrupción es demandar a los Estados firmantes la tipificación del cohecho tanto activo como pasivo, lo que ya se daba en la legislación española, pero la nueva situación internacional exigía una mejora técnica de sus contenidos, lo que se lleva a cabo especialmente en la reforma de $2010^{68}$.

La internacionalización de la corrupción es abordada directamente en estos delitos, en un primer momento, tras la reforma de 2010, con la protección de intereses financieros de la Unión Europea, que, tal como demandaban los textos por ella generados, hacía que el delito de cohecho, de acuerdo con el art.427 del código penal, comprendiera los casos en los que «los hechos sean imputados o afecten a los funcionarios de la Unión Europea o a los funcionarios nacionales de otro Estado miembro de la Unión» ${ }^{69}$. A continuación, en el mismo artículo recogía con amplitud quien merecía esta considera-

68 Vid. el análisis que lleva a cabo Matellanes Rodriguez, N., «El delito de cohecho de funcionarios nacionales en el código penal español: condicionantes internacionales y principales aspectos de su nueva regulación», en BERDUGo GóMEZ DE LA TORRE, I. y LIBERATORE S. BECHARA, A. E., Estudios sobre la corrupción. Una reflexión hispano brasileña, op. cit., en especial pp.286 y ss.

${ }^{69}$ La Convención de Mérida da un concepto más amplio de funcionario extranjero, a la que se aproxima más el Código penal español tras la reforma de 2015. En concreto el art.2 de la Convención en dos de sus apartados establece: «b) Por «funcionario público extranjero» se entenderá toda persona que ocupe un cargo legislativo, ejecutivo, administrativo o judicial de un país extranjero, ya sea designado o elegido; y toda persona que ejerza una función pública para un país extranjero, incluso para un organismo público o una empresa pública; c) Por «funcionario de una organización internacional pública» se entenderá un empleado público internacional o toda persona que tal organización haya autorizado a actuar en su nombre». 
ción $^{70}$. La reciente reforma del Código penal va más allá pues además de agravar con carácter general la pena del delito de cohecho procede a la ampliación de quien merece la consideración de funcionario extranjero equiparado al nacional, incluyendo, como demandaba la Convención de Naciones Unidas a los de cualquier Estado u organización internacional pública ${ }^{71}$.

La protección de los intereses de la Unión Europea, desde un primer momento fue más allá de esta revisión del sujeto del delito y alcanza a delitos como el fraude de subvenciones o los fraudes Tributarios que pueden estar conectados con la corrupción ${ }^{72}$.

Por otro lado, y como adelantaba la Exposición de Motivos, la reforma de 2015 ha procedido a una agravación generalizada de la respuesta penal en los «llamados delitos contra la corrupción en el ámbito de la Administración pública», muchos de los cuales pueden ser aplicables en casos de corrupción $^{73}$. Esta política criminal de agravación es además reforzada por la intro-

${ }^{70}$ El art. 427, después de la reforma de 2010 establecía: «1. Lo dispuesto en los artículos precedentes será también aplicable cuando los hechos sean imputados o afecten a los funcionarios de la Unión Europea o a los funcionarios nacionales de otro Estado miembro de la Unión. A estos efectos se entenderá que es funcionario de la Unión Europea: $1 .^{\circ}$ toda persona que tenga la condición de funcionario o de agente contratado en el sentido del Estatuto de los funcionarios de las Comunidades Europeas o del Régimen aplicable a otros agentes de la Unión Europea; $2 .^{\circ}$ toda persona puesta a disposición de la Unión Europea por los Estados miembros o por cualquier organismo público o privado que ejerza en ellas funciones equivalentes a las que ejercen los funcionarios $u$ otros agentes de la Unión Europea; $3 .^{\circ}$ los miembros de organismos creados de conformidad con los Tratados constitutivos de las Comunidades Europeas, así como el personal de dichos organismos, en la medida en que el Estatuto de los funcionarios de las Comunidades Europeas o el Régimen aplicable a otros agentes de la Unión Europea no les sea aplicable. Asimismo, se entenderá por funcionario nacional de otro Estado miembro de la Unión el que tenga esta condición a los fines de la aplicación del Derecho penal de dicho Estado miembro».

${ }^{71}$ La redacción del art.427 tras la reforma de 2015, queda como sigue: «Lo dispuesto en los artículos precedentes será también aplicable cuando los hechos sean imputados o afecten a: a) Cualquier persona que ostente un cargo o empleo legislativo, administrativo o judicial de un país de la Unión Europea o de cualquier otro país extranjero, tanto por nombramiento como por elección. b) Cualquier persona que ejerza una función pública para un país de la Unión Europea o cualquier otro país extranjero, incluido un organismo público o una empresa pública, para la Unión Europea o para otra organización internacional pública. c) Cualquier funcionario o agente de la Unión Europea o de una organización internacional pública».

72 Arroyo Zapatero, L.A. y Nieto Martin, A., Fraude y corrupción en el Derecho penal económico europeo. Eurodelitos de corrupción y fraude, op. cit.

73 De acuerdo con la Exposición de Motivos de la reforma de 2015 esta agravación generalizada en los delitos que pueden implicar corrupción dentro de la Administración pública, se lleva a cabo con un «aumento generalizado de las penas de inhabilitación es- 
ducción de una limitación para la obtención de la libertad condicional, al establecer, en el p.2 del número 4 del excesivamente extenso art.90 que se puede denegar su concesión, «cuando el penado hubiere eludido el cumplimiento de las responsabilidades pecuniarias o la reparación del daño económico causado a la Administración a que hubiere sido condenado».

Todas estas reformas del cohecho pueden vincularse también a la que hemos denominado «corrupción nacional», y muy especialmente a la necesidad de abordar su presencia en la contratación pública, a la que antes se ha hecho referencia, aunque la política criminal frente a estos comportamientos no puede limitarse al Derecho penal sino que pasa por la profundización en políticas de transparencia y por reformas en la regulación administrativa ${ }^{74}$.

La tutela de las relaciones económicas internacionales de pretender evitar su contaminación por comportamientos que quiebren la libre competencia es, como vimos, un objetivo prioritario para la OCDE, que hizo que el legislador español, incorporase como delitos en el art. 445 del Código penal conductas de corrupción en las transacciones comerciales internacionales ${ }^{75}$. En 2013, la OCDE emite un informe «demoledor» ${ }^{76}$ sobre la situación en España, al constatar que durante toda su vigencia, no se había producido ni una sola condena ${ }^{77}$.

pecial para empleo o cargo público», a la que une en los supuestos de más gravedad la de ejercicio de sufragio pasivo.

${ }^{74}$ En especial, sobre contenidos de políticas preventivas frente a la corrupción en las administraciones públicas, puede consultarse los estudios recogidos en el primer capítulo de ya citada obra de Nieto Martín, A. y Maroto Calatayud, M. (Dirs.), Public Compliance. Prevención de la corrupción en administraciones públicas y partidos políticos, op. cit., pp. 17 a 130.

${ }^{75}$ Este delito se introduce en el Código penal español por la L.O. 3 del año 2000, sobre esta primera redacción véase FABIÁN CAPARRÓs, E., La corrupción de agente público extranjero e internacional, Tirant lo Blanch, Valencia, 2003. La actual redacción del artículo proviene de la reforma de 2003 y fue revisado en la de 2010. Sobre este delito es básica la citada monografía de BENITO SÁNCHEZ, D., El delito de corrupción en las transacciones comerciales internacionales, op. cit., pp. 145 y ss.

${ }^{76}$ El Grupo de trabajo efectuó en la fase 2, en 2006, una serie de recomendaciones que afectan a la corrupción transnacional. A resaltar que en su Informe el Grupo de trabajo de la OCDE constata no se ha seguido ninguna de las tres referidas a la «infracción de corrupción transnacional», ninguna de las dos concernientes a la «responsabilidad de las personas jurídicas en caso de corrupción transnacional» y ninguna de las cinco referidas a las «sanciones aplicables a la corrupción transnacional». Vid. OCDE, Rapport de phase 3 sur la mise en oeuvre par l'Espagne de la Convention de l'OCDE sur la lutte contre la corruption, decembre 2012, p. 92 y ss., en < http://www.oecd.org/fr/daf/anti-corruption/ Espagne-Phase-3-FR.pdf $>$ (último acceso: 14.5.2015).

77 Textualmente afirma: «El Grupo de trabajo esta extremadamente preocupado por el hecho de que después de casi 13 años desde la entrada en vigor de la infracción de corrupción transnacional en España, ninguna persona física o moral haya sido perseguida o condenada por este tema». Vid. OCDE: Rapport de phase 3..., op. cit., p.5. El Informe, 
Con lo que se confirma una evidencia que una cosa son las leyes y otra muy distinta la realidad de su aplicación.

Esta situación hace que el autor de la última reforma busque un nuevo camino para dar cabida a estos comportamientos dentro de la sección $4^{\text {a }}$ del Capitulo XI del Título XIII del libro II, hasta ahora denominada «De la corrupción entre particulares», que pasa a titularse «De la corrupción en los negocios» ${ }^{78}$. El legislador, con una técnica cuanto menos estética y sistemáticamente discutible ${ }^{79}$, suprime el capítulo X del Título XIX, «De los delitos de corrupción en las transacciones comerciales internacionales» e incluye su contenido, que prácticamente reproduce el del ya farragoso antiguo art. 445, en el nuevo art. $286 \operatorname{ter}^{80}$.

La nueva redacción, no resuelve el problema derivado de la reforma del cohecho, que al ampliar el concepto de funcionario hace que sean incluibles

pp.10 y 11, constata la existencia de cuatro asuntos en los que se inició una investigación que concluyó en archivo. En concreto, cinco se referían a relaciones comerciales con distintos países, Costa Rica, Libia, Angola, Marruecos y Letonia y dos a programas internacionales de contenido económico, uno referido a comercio de material militar y otro al programa de Naciones Unidas, «petróleo contra alimentos».

${ }_{78}$ Esta denominación se incorpora en el debate de la reforma en el Senado y sustituye a la de «corrupción en el sector privado», que había aprobado el Congreso.

79 Aunque requiere una mayor profundización, no parecía técnicamente necesario el cambio de ubicación de este delito. El Senado con el señalado cambio de denominación de la Sección, de «corrupción en el sector privado», a «delitos de corrupción en los negocios», salva la obvia objeción de que era difícil hablar de corrupción privada, cuando uno de los sujetos de la relación de corrupción es «autoridad o funcionario público», aunque lo sea de otro país, máxime cuando su intervención se efectúa «en relación con el ejercicio de funciones públicas».

${ }^{80}$ El nuevo art.286 ter. «1. Los que mediante el ofrecimiento, promesa o concesión de cualquier beneficio o ventaja indebidos, pecuniarios o de otra clase, corrompieren o intentaren corromper, por sí o por persona interpuesta, a una autoridad o funcionario público en beneficio de estos o de un tercero, o atendieran sus solicitudes al respecto, con el fin de que actúen o se abstengan de actuar en relación con el ejercicio de funciones públicas para conseguir o conservar un contrato, negocio o cualquier otra ventaja competitiva en la realización de actividades económicas internacionales, serán castigados, salvo que ya lo estuvieran con una pena más grave en otro precepto de este Código, con las penas de prisión de prisión de tres a seis años, multa de doce a veinticuatro meses, salvo que el beneficio obtenido fuese superior a la cantidad resultante, en cuyo caso la multa será del tanto al triplo del montante de dicho beneficio.

Además de las penas señaladas, se impondrá en todo caso al responsable la pena de prohibición de contratar con el sector público, así como la pérdida de la posibilidad de obtener subvenciones o ayudas públicas y del derecho a gozar de beneficios o incentivos fiscales y de la Seguridad Social, y la prohibición de intervenir en transacciones comerciales de trascendencia pública por un periodo de siete a doce años.

2. A los efectos de este artículo se entenderá por funcionario público los determinados por los artículos 24 y $427 »$. 
en él todos los comportamientos de este cohecho internacional del 286 ter. Tampoco la regla para el concurso de leyes que contiene este artículo, «salvo que ya lo estuvieran con una pena más grave en otro precepto de este Código», supone una ayuda para solucionar estos problemas ${ }^{81}$.

En cualquier caso, entiendo que es difícil de sostener, que la no aplicación de la corrupción en las relaciones económicas internacionales dependa del lugar de su ubicación en el Código.

Las obligaciones internacionales de España, generadas tanto por la Convención de Mérida, aunque no la mencione, como en especial por «la trasposición de la Decisión Marco 2003/568/JAI relativa a la lucha contra la corrupción en el sector privado» llevaron al legislador, en 2010, ciertamente con bastante retraso, a incorporar al código estas conductas de corrupción privada en el nuevo artículo 286 bis, con lo que pasaban a un primer plano las consecuencias económicas de la corrupción y la protección de la libre competencia $^{82}$. El artículo en la reforma del Código de 2015 es objeto de un cambio de orden en sus dos primeros párrafos, con lo que sigue la misma sistemática del cohecho, en primer lugar se tipifica la conducta del corrupto y en segundo lugar la de quien corrompe.

${ }^{81}$ Sobre la regla del concurso de leyes que plantea el legislador en la nueva redacción, mi discípula, la profesora BENITO SÁNCHEZ argumenta con razón que tampoco tiene mucho sentido, pues, valiéndonos de dos ejemplos, conduce a la siguiente situación:

a) Ciudadano español que soborna a un funcionario marroquí para que éste realice un acto contrario a los deberes del cargo (cohecho propio) y obtener así un beneficio en la realización de actividades comerciales internacionales.

b) Ciudadano español que soborna a funcionario marroquí para que éste realice un acto propio del cargo (cohecho impropio) y obtener así un beneficio en la realización de actividades comerciales internacionales.

En el primer caso, hay que resolver cual es el precepto aplicable: el nuevo 286 ter o el nuevo 427 relacionado con el 424 a su vez relacionado con el 420? Al tener ambos la misma pena, no nos sirve la regla expresada por el legislador. Por lo que habría que acudir a las reglas generales del art.8 CP y el precepto más especial sería el 286 ter.

En el segundo caso, sería aplicable el 286 ter porque prevé una pena mayor que el cohecho propio «clásico» (424 y 420). Esta situación abre la duda de cuáles son las razones que llevan a castigar con más pena el cohecho propio «extranjero» que el cohecho propio «nacional», tal vez tiene que ver con el bien jurídico afectado. BENITo SÁNCHEZ, D., «Análisis crítico de las modificaciones al delito de corrupción en las transacciones comerciales internacionales en el proyecto de reforma del código penal», comunicación presentada en el Congreso Internacional Transparencia institucional, participación ciudadana, actividad política y lucha contra la corrupción, Universidad de las Palmas de Gran Canaria, 27 marzo 2015.

${ }^{82}$ Sobre el debate en torno al bien jurídico que refleja distintas posiciones en Derecho comparado, vid. Berdugo Gómez De La Torre, I. y Cerina, G., «Sobre la corrupción entre particulares. Convenios internacionales y Derecho comparado», op. cit., p.159 y ss. Los mismos: Algunas observaciones sobre la corrupción entre particulares en el Código penal español, en Revista Brasileira de Ciencias Criminais, 97, 2012, p.217. 
El legislador aprovechó la ocasión para dar directa trascendencia penal, en el párrafo 4 del mismo artículo, de una forma más que discutible, a la corrupción en el deporte, pues, entre otras cosas, es bastante difícil establecer que sea el mismo bien jurídico protegido en este delito y en la corrupción de particulares ${ }^{83}$.

La reforma de 2015 ha pretendido solventar alguna de estas objeciones formuladas por la doctrina a esta nueva figura delictiva. En este sentido incorpora la exigencia de que el encuentro o competición en el que se ha dado la corrupción sea de «especial relevancia económica o deportiva» ${ }^{84}$ y establece a continuación cuando entiende que concurre esta clase de relevancia. El camino más adecuado, en mi opinión, hubiera sido el exigir la presencia conjunta de ambas relevancias ${ }^{85}$. Desde una consideración político criminal parece que la mencionada relevancia económica o deportiva, donde concurre es en los supuestos de agravación que recoge el 286 quater $^{86}$, que por otro

83 Vid. Berdugo Gómez De La Torre, I. y Cerina, G., Algunos aspectos del nuevo delito de corrupción en el deporte, en BERdugo Gómez De LA TORRE, I. y LiBERATORE S. BECHARA, A. E. (coords.), Estudios sobre la corrupción. Una reflexión hispano brasileña, op. cit., pp. 387 y ss. Sobre este delito pueden consultarse las monografías de CoRTÉs Bechiarelli, E., El delito de corrupción deportiva, Tirant lo Blanch, Valencia 2011 y Benítez Ortuzar, I. F., El delito de "fraudes deportivos», Dykinson, Madrid 2011.

${ }^{84}$ La nueva redacción del art 281 bis 4 . establece «Lo dispuesto en este artículo será aplicable, en sus respectivos casos, a los directivos, administradores, empleados o colaboradores de una entidad deportiva, cualquiera que sea la forma jurídica de ésta, así como a los deportistas, árbitros o jueces, respecto de aquellas conductas que tengan por finalidad predeterminar o alterar de manera deliberada y fraudulenta el resultado de una prueba, encuentro o competición deportiva de especial relevancia económica o deportiva».

A estos efectos, se considerará competición deportiva de especial relevancia económica, aquélla en la que la mayor parte de los participantes en la misma perciban cualquier tipo de retribución, compensación o ingreso económico por su participación en la actividad; y competición deportiva de especial relevancia deportiva, la que sea calificada en el calendario deportivo anual aprobado por la federación deportiva correspondiente como competición oficial de la máxima categoría de la modalidad, especialidad, o disciplina de que se trate».

${ }^{85}$ El camino seguido por el legislador es ciertamente discutible. Pues vincula la relevancia económica a la existencia de cualquier modo de retribución, aunque no lo sea en todos los participantes, con lo que puede ser sujeto del delito uno de los participantes que no recibe retribución. Además, por otro lado, la retribución puede ser mínima. Entiendo que la «especial relevancia económica» tenía que haberse vinculado al otro criterio el de la «especial relevancia deportiva», que además el legislador define. La vinculación de los dos criterios proporcionaría una explicación a la inclusión de estos comportamientos en este lugar del Código.

86 «En el caso del apartado 4 del artículo 286 bis, los hechos se considerarán también de especial gravedad cuando:

a)tengan como finalidad influir en el desarrollo de juegos de azar o apuestas; o

b) sean cometidos en una competición deportiva oficial de ámbito estatal calificada como profesional o en una competición deportiva internacional». 
lado permitiría acomodar la respuesta penal a las exigencias constitucionales de racionalidad en el recurso por el legislador a la utilización del Derecho penal.

La financiación de los partidos políticos ha sido desde hace mucho tiempo $^{87}$, uno de los puntos más sensibles a la presencia de la corrupción. La mayor parte de estas conductas ya tenían relevancia penal a través de distintas figuras del Código penal, pero, ciertamente, como recuerda la Exposición de Motivos de la reforma de 2015, no existía en nuestro Código penal una figura que recogiera de modo expreso esta forma de corrupción y «con esta modificación se castigará a aquellas personas que acepten y reciban donaciones ilegales o que participen en estructuras u organizaciones cuyo principal objeto sea el de financiar ilegalmente a un partido político».

Para lograr este objetivo introduce en el Libro II un nuevo Título XIII bis, «De los delitos de financiación ilegal de los partidos políticos», integrado por los dos nuevos artículos 304 bis y 304 ter.

La eficacia de cualquier política criminal pasa por tener presente que esta no puede reducirse al recurso al Derecho penal y esto sin duda ocurre también respecto a la corrupción referida a los partidos políticos que, además, no se puede limitar a la consideración como delitos independientes de estas conductas. También son exigibles tanto conductas internas de transparencia como la existencia de controles externos de sus finanzas ${ }^{88}$, todo ello unido a no hacer depender la responsabilidad política de sus miembros o dirigentes de su eventual responsabilidad penal.

La búsqueda de eficacia en la lucha contra el delito lleva al legislador a veces en la tensión eficacia garantía a plantear el sacrificio de garantías en búsqueda de resultados contra el delito, que no llegan a producirse. Este rasgo clásico de la utilización simbólica del Derecho penal aparece también en un campo como el de la corrupción en el que el peso de la opinión pública es particularmente elevado.

Esta situación se ha plasmado en algunos ordenamientos, con el apoyo en la Convención de Mérida ${ }^{89}$, en la inclusión del delito de enriquecimiento ilícito. Ciertamente en el posible debate en España tiene que pesar la posición

${ }^{87}$ El caso FILESA fue cerrado por la STS de 18 de Octubre de 1997.

88 Vid. en Nieto Martín, A. y Maroto Calatayud, M., Public compliance. Prevención de la corrupción en administraciones públicas y partidos políticos, op. cit, en especial los estudios recogidos en los capítulos II y III, pp. 131 y ss.

${ }^{89} \mathrm{El}$ art. 20 de la Convención de Mérida abre esta posibilidad, aunque la supedita a los principios fundamentales de cada ordenamiento jurídico nacional. En concreto dispone que: «Con sujeción a su constitución y a los principios fundamentales de su ordenamiento jurídico, cada Estado Parte considerará la posibilidad de adoptar las medidas legislativas y de otra índole que sean necesarias para tipificar como delito, cuando se cometa intencionalmente, el enriquecimiento ilícito, es decir, el incremento significativo del pa- 
del Tribunal constitucional portugués ${ }^{90}$ rechazando esta figura delictiva, por contravenir las exigencias constitucionales, en especial de presunción de inocencia.

Un tipo penal con este contenido está construido como un delito de sospecha, por tanto manifestación de una responsabilidad objetiva, al elevar a la consideración de delito, lo que en realidad constituye una prueba indiciaria, la no justificación por parte de un funcionario de un incremento patrimonial, la sospecha, por tanto, de la comisión de un posible hecho delictivo. Una figura de esta naturaleza implica, por tanto, un ataque a la presunción de inocencia y una inversión de la carga de la prueba ${ }^{91}$.

Todos los informes internacionales sobre la corrupción en España ponen de manifiesto una presencia particularmente importante de la misma en el ámbito municipal, proyectada sobre todo en los excesos que se produjeron en el urbanismo y en la ordenación del territorio para favorecer un desordenado y enloquecido auge de la construcción.

La respuesta penal expresa comienza a producirse en el Código de 1995 , tras un frustrado intento en el Proyecto de $1980,{ }^{92}$ con la incorporación al mismo de un capítulo titulado «De los delitos sobre la ordenación del territorio».

En las casi dos décadas de vigencia del código ha quedado evidente la realidad de la corrupción a gran escala en algunos municipios dentro de las decisiones de política urbanística ${ }^{93}$, lo que hizo necesaria la adaptación de la

trimonio de un funcionario público respecto de sus ingresos legítimos que no pueda ser razonablemente justificado por él».

${ }^{90}$ El Tribunal Constitucional portugués declaró inconstitucional el delito de enriquecimiento ilícito que se había incorporado al Código penal, fundamentalmente por suponer una inversión de la carga de la prueba, vid. Acórdão do Tribunal Constitucional $\mathrm{n}^{\mathrm{o}}$ 179/2012, Processo no 182/12 <http://www.tribunalconstitucional.pt/tc/acordaos/20120179.html>, (último acceso: 14.5.2015).

${ }^{91}$ En este sentido puede verse la argumentación que para rechazar la pretensión de su inclusión en el Derecho penal brasileño manteníamos en BERdugo GómEz DE LA TORRE, I. y Liberatore S. BecharA, A. E., «O controle da corrupçao: a experiencia a española», op. cit., pp. 373-374.

92 Vid. Vercher Noguera, Antonio, «Urbanismo y corrupción: notas sobre el proceso evolutivo de su tratamiento penal en España», en BERdugo Gómez De LA TorRe, Ignacio/Liberatore S.Bechara, Ana Elisa (Coords.), Estudios sobre la corrupción ..., op. cit., p. 415. También se habían producido, como recoge el mismo autor, p. 424 y ss., algunos antecedentes jurisprudenciales, dentro de la aplicación de los delitos contra el medio ambiente.

${ }^{93}$ Es particularmente significativo el caso del municipio de Marbella. Entre los distintos pronunciamientos jurisprudenciales puede verse el reciente de la conocida como «operación Malaya», sobre el que recayó sentencia de la Audiencia Provincial de Málaga de más de 4.000 folios. Con independencia de otras consideraciones, el caso en este mo- 
respuesta penal a esta realidad y el reforzamiento de las regulaciones administrativas. Estas reformas y en especial el contenido de la legislación administrativa excederían el objetivo de estas líneas, por su amplitud y al ser además una materia de competencia de las distintas comunidades autónomas. En el campo del Derecho penal, la reforma de 2010, cambia la rúbrica del capítulo, que pasa a denominarse «De los delitos sobre la ordenación del territorio y el urbanismo», amplia los tipos y agrava las penas y modifica la denominada prevaricación urbanística ${ }^{94}$.

La abundancia de elementos normativos en los artículos 319 y 320 ha requerido un importante y complejo desarrollo jurisprudencial para la determinación del contenido de los mismos ${ }^{95}$. La reforma de 2015, ha incorporado en el último momento, una precisión respecto a «la demolición de la obra y la reposición de la realidad física alterada», que abre un nuevo campo de debate sobre la suspensión de la demolición ${ }^{96}$.

Junto a estas figuras que tipifican comportamientos de uso desviado del poder, existe otra serie de delitos que engloban no sólo conductas de corrupción, un claro ejemplo es el delito de blanqueo de capitales ${ }^{97}$. Desde que la Ley Orgánica 1/1988, de 24 de marzo, incorporara al viejo Código Penal español la primera criminalización del blanqueo de capitales, tanto la regulación como la práctica de este delito han experimentado cambios trascendentales.

Las sucesivas reformas que el legislador ha introducido a lo largo de más de dos décadas han transformado radicalmente la naturaleza esta figura ${ }^{98}$. En

mento tras haberse celebrado ya la vista del recurso en julio de 2014 , pendiente de la sentencia definitiva del Tribunal Supremo resolviendo los muchos recursos presentados por parte de los 52 condenados.

${ }_{94}$ Sobre la nueva redacción véase RUBIO LARA, P. A., «Corrupción urbanística y corrupción pública en el Derecho penal: un estudio de la situación tras la reforma de 2010», en AA.VV., La corrupción a examen, Aranzadi, Pamplona, 2012, p. 17 y ss.

${ }_{95}$ Sirvan de ejemplo los términos que enumera Vercher NogUera, A., «Urbanismo y corrupción: notas sobre el proceso evolutivo de su tratamiento penal en España», op. cit., p. 429 y ss., como «constructor y promotor», «construcción»o «edificación» o «demolición».

${ }_{96}$ En su paso por el Senado se incorporó, en el apartado 3 del art. 319, tras el establecimiento de las indemnizaciones a debidas a terceros de buena fe, que los tribunales «valorando las circunstancias, y oída la Administración competente, condicionarán temporalmente la demolición a la constitución de garantías que aseguren el pago de aquellas».

97 Sobre este delito véase la clásica monografía del especialista en esta materia, FABiÁn CAPArRós, E., El delito de blanqueo..., op. cit., o las de Abel Souto, M., Universidad de Santiago de Compostela: Santiago de Compostela, 2002 y El delito de blanqueo en el Código penal español, Bosch, Barcelona, 2005.

98 Presenta un alto interés los sucesivos congresos internacionales, cuatro hasta ahora, que se han celebrado en torno al blanqueo coordinados por ABEL Souto, M. y SÁncheZ 
efecto, tanto la referida normativa original como la que se incorporó al mismo cuerpo legal por obra de la Ley Orgánica 8/1992 centraron sus esfuerzos en la lucha contra el narcotráfico, pretendiendo hallar su contenido material en torno a la protección de la salud pública. En tal sentido, fue determinante la influencia de la Convención de Naciones Unidas contra el tráfico ilícito de estupefacientes y sustancias psicotrópicas, hecha en Viena el 19 de diciembre de $1988^{99}$.

La Ley Orgánica 10/1995, aprobatoria del nuevo Código Penal, ofreció a este delito una nueva regulación sobre la que se ha venido construyendo la autonomía del delito de blanqueo que reclaman los nuevos instrumentos internacionales, fundada sobre el significado socioeconómico de este género de conductas. Lo que posibilita su aplicación a conductas complementarias de la de corrupción al favorecer el disfrute de los beneficios de la misma.

Las sucesivas reformas operadas por las Leyes Orgánicas 15/2003 y $5 / 2010$ - de la que deriva la regulación hoy vigente- han consolidado esta tendencia. Con todo, aún existen ciertas manifestaciones, tanto normativas como jurisprudenciales, que demuestran que todavía queda camino por recorrer $^{100}$.

STEWART, N., sus ponencias y conclusiones, referidas no sólo al Derecho penal, han sido objeto de publicación: I Congreso de Prevención y Represión del blanqueo de dinero, Tirant lo Blanch, Valencia, 2009; II Congreso sobre Prevención y Represión del Blanqueo de Dinero Tirant lo Blanch, Valencia, 2011; III Congreso sobre Prevención y Represión del Blanqueo de Dinero Tirant lo Blanch, Valencia, 2012; IV Congreso sobre Prevención y Represión del Blanqueo de Dinero Tirant lo Blanch, Valencia 2014.

${ }_{99} \mathrm{El}$ art.3. 1, de la Convención de Viena obliga a los Estados signatarios a considera como delito entre otros a: «b) i) la conversión o la transferencia de bienes a sabiendas de que tales bienes proceden de alguno o algunos de los delitos tipificados o de conformidad con el inciso a) del presente párrafo, o de un acto de participación en tal delito o delitos, con objeto de ocultar o encubrir el origen ilícito de los bienes o de ayudar a cualquier persona que participe en la comisión de tal delito o delitos a eludir las consecuencias jurídicas de sus acciones; ii) la ocultación o el encubrimiento de la naturaleza, el origen, la ubicación, el destino, el movimiento o la propiedad reales de bienes, o de derechos relativos a tales bienes, a sabiendas de que proceden de alguno o algunos de los delitos tipificados de conformidad con el inciso a) del presente párrafo o de un acto de participación en tal delito o delitos»; Texto completo de la Convención, ratificada por España, puede consultarse en: «BOE» núm. 270, de 10 de noviembre de 1990.

100 Así aunque se considera al blanqueo como delito autónomo de la infracción previa, aún hay vestigios de su dependencia, como es el caso de la agravación si los bienes proceden de las drogas del art. 301.II (desde 1995) o de la corrupción o el medio ambiente 301.III, o la agravación personal en el art. 303 a veterinarios, facultativos, educadores... (nótese que el art. 303 es clónico del art. 372, sobre drogas). Por otro lado, hay una desatada tendencia a castigar como blanqueo actos que no tienen nada que ver con lo socioeconómico, que es el fundamento de la autonomía, utilizando la amplitud del tipo. Aparte, aún quedan asuntos por resolver en el plano dogmático. Por ejemplo, el problema del sujeto activo en el blanqueo 
La objeción más importante es la excesiva amplitud del tipo, constitucionalmente cuestionable y que puede llevar a castigar como iguales comportamientos que no lo son y a alejarse del bien jurídico originalmente protegido $^{101}$.

La Parte General del Código penal también ha sido objeto de reformas vinculadas al Derecho penal económico y aplicables a la lucha contra la corrupción y que eran apuntadas en los instrumentos internacionales que se han expuesto. En concreto, nos referimos a la responsabilidad penal de las personas jurídicas y al decomiso.

La necesidad de que las personas jurídicas, cuando infringen las normas reguladoras de la economía, fueran objeto del poder sancionador del Estado, bien penal, bien administrativo, aparecía, como hemos visto, en varios instrumentos internacionales ${ }^{102}$.

En España, la responsabilidad penal de las personas jurídicas, se incorpora al Código penal en la Reforma de 2010 en el nuevo artículo 31 bis $^{103}$. La reforma discurre paralela a un debate doctrinal sobre la necesidad de su admisión y sobre la finalidad última de esta modificación del Código ${ }^{104}$ y vino seguida de cambios necesarios en la Ley de Enjuiciamiento Criminal ${ }^{105}$ y de

imprudente. Gramaticalmente es común, pero el TS se pronuncia 50-50\% afirmando que es especial, afectando sólo a los sujetos obligados por la Ley 10/2010 de prevención. Cuando se opta por el especial, se dice que el deber objetivo de cuidado sólo se puede determinar a partir de una norma de referencia, y esa norma sería la Ley 10/2010.

${ }^{101}$ Por todos ver las críticas que expresa y recoge ABEL Souto, A., «Jurisprudencia penal reciente sobre el blanqueo de dinero, volumen del fenómeno y evolución del delito en España», en IV Congreso sobre Prevención y Represión del Blanqueo de Dinero, op. cit., en especial en pp. 138 a 140.

102 Puede consultarse en especial respecto a la situación en Europa, DE LA CuESTA ARZAMENDI, J.L. y PÉREZ MACHíO, A. I., «La responsabilidad penal de las personas jurídicas en el marco europeo: las Directivas europeas y su implementación por los Estados», en DE LA Cuesta Arzamendi, J. L. (Dir.)/De La Mata Barranco, N. (Coords.), Responsabilidad penal de las personas jurídicas, Thomson Reuters Aranzadi, Madrid 2013, pp. 129 y ss.

${ }^{103}$ Sobre la incorporación al Derecho penal español de la responsabilidad penal de las personas jurídicas, la necesidad de esta decisión, antecedentes y aproximación a los problemas que plantea, vid. la aproximación que se lleva a cabo en BERDUGo GómEz DE LA Torre, I., Viejo y nuevo Derecho Penal. Principios y desafios del Derecho penal de hoy, op. cit., pp.161 y ss.

${ }^{104}$ Una buena síntesis del debate y de las distintas posturas sostenidas puede verse en PALma Herrera, J. M., «El papel de las compliance en un modelo vicarial de responsabilidad penal de la persona jurídica», en Palma Herrera, J. M. (Dir.), Procedimientos operativos estandarizados y responsabilidad penal de la persona jurídica, Dykinson, Madrid 2014, pp.158 y ss.

105 Sobre este punto vid. el reciente artículo de RodRíGUEz GARCíA, N., «Adecuación del proceso penal español a la fijación legal de la responsabilidad criminal de las personas jurídicas», Revista Penal 35, 2015, pp. 139 y ss. 
una modificación del artículo en diciembre de 2012 para incluir dentro de las personas jurídicas susceptibles de responsabilidad penal a los, hasta entonces excluidos, partidos políticos y sindicatos ${ }^{106}$.

El examen de muchos de los informes citados en el primer apartado de este trabajo pone de relieve como la mayor parte de las conductas de gran corrupción son llevados a cabo por o a través de una o varias personas jurídicas por lo que dotar de eficacia a la respuesta penal frente a la actuación de las mismas es necesario si se busca una política eficaz frente a la corrupción.

Entiendo, de acuerdo con un importante sector doctrinal ${ }^{107}$, que la razón de ser de la admisión de la responsabilidad penal de las personas jurídicas descansa en la pretensión de buscar que las mismas establezcan controles internos, que impidan o dificulten el que a través de ella se realicen comportamientos delictivos, entre ellos los que implican una utilización desviada del poder político, del poder económico o de ambos ${ }^{108}$.

La reforma de 2015, de acuerdo con su Exposición de Motivos, en este punto se lleva a cabo «con la finalidad de delimitar adecuadamente el contenido del «debido control», cuyo quebrantamiento permite fundamentar su responsabilidad penal». El legislador, con su mencionado entusiasmo en la numeración de los artículos, completa y desglosa el art.31 bis originario hasta un art.31bis quinquies. La principal innovación de la reforma radica en establecer los contenidos que deben abordar los denominados «modelos de organización ${ }^{109} \mathrm{y}$ cuando la presencia de estos, aunque se hayan quebranta-

106 Según la Exposición de Motivos de la Ley Orgánica 7/2012 de 27 de diciembre por la que se modificaba el Código penal, «De este modo se supera la percepción de impunidad de estos dos actores de la vida política que trasladaba la anterior regulación». Pero hay que recordar que la percepción a la que se refiere el legislador sólo logra romperse con la aplicación de la ley, cosa que hasta el momento no se ha producido. Los riesgos del recurso a la utilización simbólica del Derecho penal aparecen cuando, como es el caso, un precepto no llega a aplicarse y la mencionada percepción es de que si hubiera sido posible hacerlo.

107 Por todos Nieto Martin, A., La responsabilidad penal de la personas jurídicas un modelo legislativo, Iustel, Madrid, 2008.

108 Hasta ahora existen muy pocas imputaciones a personas jurídicas. Quizá entre las que más repercusión han tenido están la imputación al FC Barcelona, a Bankia y a Pescanova. Sin embargo, sí es cierto que van apareciendo casos en los tribunales e incluso existe alguna sentencia condenatoria, aunque no significativa. Así, la SAP de Zaragoza, sec. $6^{\mathrm{a}}, \mathrm{n}^{\mathrm{o}} 337 / 2014$, de 25 de noviembre, y la SAP de Madrid, sec. $3^{\mathrm{a}}, \mathrm{n}^{\mathrm{o}} 742 / 2014$, de 17 de diciembre, en ambos casos por delito de estafa. Agradezco a la profesora Soledad GIL NoBAJAS de la Universidad de Deusto esta información.

109 El art. 31 bis apartado 5 enumera los puntos que debe contener el modelo de organización: «Los modelos de organización y gestión a que se refieren la condición $1 .^{\mathrm{a}}$ del apartado 2 y el apartado anterior deberán cumplir los siguientes requisitos: 
do, puede determinar la exención de responsabilidad penal de la persona jurídica en cuyo «nombre o por cuenta de las mismas y en su beneficio directo $\mathrm{o}$ indirecto ${ }^{110}$ se haya realizado el delito.

Pero la reforma, aunque mantiene la posible responsabilidad penal de partidos y sindicatos, continua excluyendo de la misma a personas jurídicas que con carácter general «ejerzan potestades públicas de soberanía o administrativas» ${ }^{111}$.

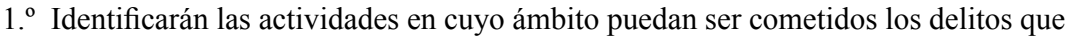
deben ser prevenidos.

$2 .^{\circ}$ Establecerán los protocolos o procedimientos que concreten el proceso de formación de la voluntad de la persona jurídica, de adopción de decisiones y de ejecución de las mismas con relación a aquéllos.

3. Dispondrán de modelos de gestión de los recursos financieros adecuados para impedir la comisión de los delitos que deben ser prevenidos.

4. Impondrán la obligación de informar de posibles riesgos e incumplimientos al organismo encargado de vigilar el funcionamiento y observancia del modelo de prevención.

5. Establecerán un sistema disciplinario que sancione adecuadamente el incumplimiento de las medidas que establezca el modelo.

6. ${ }^{\circ}$ Realizarán una verificación periódica del modelo y de su eventual modificación cuando se pongan de manifiesto infracciones relevantes de sus disposiciones, o cuando se produzcan cambios en la organización, en la estructura de control o en la actividad desarrollada que los hagan necesarios»».

${ }^{110} \mathrm{El}$ art. 31bis 2, en sus cuatro primeros apartados establece: «Si el delito fuere cometido por las personas indicadas en la letra a) del apartado anterior, la persona jurídica quedará exenta de responsabilidad si se cumplen las siguientes condiciones:

1. ${ }^{\circ}$ el órgano de administración ha adoptado y ejecutado con eficacia, antes de la comisión del delito, modelos de organización y gestión que incluyen las medidas de vigilancia y control idóneas para prevenir delitos de la misma naturaleza o para reducir de forma significativa el riesgo de su comisión;

2. ${ }^{a}$ la supervisión del funcionamiento y del cumplimiento del modelo de prevención implantado ha sido confiada a un órgano de la persona jurídica con poderes autónomos de iniciativa y de control o que tenga encomendada legalmente la función de supervisar la eficacia de los controles internos de la persona jurídica;

3. ${ }^{\mathrm{a}}$ los autores individuales han cometido el delito eludiendo fraudulentamente los modelos de organización y de prevención y

4. ${ }^{\mathrm{a}}$ no se ha producido una omisión o un ejercicio insuficiente de sus funciones de supervisión, vigilancia y control por parte del órgano al que se refiere la condición $2 .{ }^{\mathrm{a}}$.

En los casos en los que las anteriores circunstancias solamente puedan ser objeto de acreditación parcial, esta circunstancia será valorada a los efectos de atenuación de la pena».

111 El art.31 quinquies establece:

«1. Las disposiciones relativas a la responsabilidad penal de las personas jurídicas no serán aplicables al Estado, a las Administraciones públicas territoriales e institucionales, a los Organismos Reguladores, las Agencias y Entidades públicas Empresariales, a las organizaciones internacionales de derecho público, ni a aquellas otras que ejerzan potestades públicas de soberanía o administrativas. 
Desde una perspectiva político criminal esta exclusión requiere una profundización en el debate, pues la política de prevención de la corrupción tiene una pieza clave en la actuación o en la intervención de las personas jurídicas en las que se articula la Administración y esta prevención no debe excluir sin más un posible recurso frente a ellas de la sanción penal.

Uno de los más importantes desafíos políticos criminales dentro de la criminalidad económica vinculada a la delincuencia organizada y dentro de ella a los delitos de corrupción, es recuperar el dinero o los bienes vinculados a estas actividades delictivas. A esta finalidad obedece la Directiva de 3 de Abril del 2014, que el legislador español utiliza como referencia en la reforma de 2015.

La ampliación del decomiso en el Código penal, iniciada en 2010, abandona la regulación tradicional del mismo, vinculada directamente a la realización de un hecho delictivo. La Directiva abre la puerta del decomiso ampliado, que el legislador español cruza, y que ya había utilizado en 2010 para los delitos de terrorismo y los cometidos por grupos u organizaciones criminales.

$\mathrm{El}$ art.127 bis establece el «decomiso de los bienes, efectos y ganancias» en una extensa relación de delitos entre los que se encuentran relacionados con la corrupción: delitos de corrupción en los negocios, delitos de blanqueo de capitales, delitos de cohecho y delitos de malversación. El decomiso se establece, de acuerdo con el mencionado artículo, cuando el juez o tribunal «resuelva, a partir de indicios objetivos fundados, que los bienes o efectos provienen de una actividad delictiva y no se acredite su origen lícito».

El decomiso no requiere por tanto la conexión causal entre el delito por el que se condena y los bienes, efectos y ganancias decomisados. Sino que establece una presunción de su origen ilícito en función de pruebas indiciarias, que enumera en el apartado 2 del mismo artículo 127 bis $^{112}$. La regulación se

2. En el caso de las Sociedades mercantiles públicas que ejecuten políticas públicas o presten servicios de interés económico general, solamente les podrán ser impuestas las penas previstas en las letras a) y g) del apartado 7 del artículo 33. Esta limitación no será aplicable cuando el juez o tribunal aprecie que se trata de una forma jurídica creada por sus promotores, fundadores, administradores o representantes con el propósito de eludir una eventual responsabilidad penal».

112127 bis $2:$ «1. ${ }^{\circ}$ La desproporción entre el valor de los bienes y efectos de que se trate y los ingresos de origen lícito de la persona condenada.

2. ${ }^{\circ}$ La ocultación de la titularidad o de cualquier poder de disposición sobre los bienes o efectos mediante la utilización de personas físicas o jurídicas o entes sin personalidad jurídica interpuestos, o paraísos fiscales o territorios de nula tributación que oculten o dificulten la determinación de la verdadera titularidad de los bienes.

3. La transferencia de los bienes o efectos mediante operaciones que dificulten o impidan su localización o destino y que carezcan de una justificación legal o económica válida.

3. En estos supuestos será también aplicable lo dispuesto en el apartado 3 del artículo anterior. 
completa con la detallada regulación de otros puntos como los supuestos en que no requiere sentencia condenatoria y el decomiso de bienes transferidos a un tercero ${ }^{113}$.

La regulación del decomiso, no sólo en lo que se refiere a la corrupción, es ejemplo de la búsqueda de eficacia con el precio de la tensión con las garantías de las que es titular el ciudadano delincuente, también el corrupto. Pese a la necesidad de pruebas indiciarias y del contenido de la Directiva inspiradora y de afirmaciones del Tribunal Europeo de Derechos Humanos de que «el decomiso sin condena no tiene una naturaleza penal», que recoge la Exposición de Motivos, se abren dudas desde un derecho penal de garantías, en especial en lo que se refiere a su proximidad al delito de enriquecimiento ilícito, también mencionada en la Exposición de Motivos.

\section{CONCLUSIÓN}

En las últimas décadas se ha producido una expansión de la corrupción, que la ha llevado a potenciar sus efectos negativos y a presentar consecuencias en nuevos ámbitos. Sus efectos expansivos, en especial sobre las relaciones económicas, hacen pasar a un primer plano su dimensión internacional.

Los organismos internacionales llevan una política activa frente a la corrupción transfronteriza o la que afecta a las relaciones económicas internacionales

4. Si posteriormente el condenado lo fuera por hechos delictivos similares cometidos con anterioridad, el juez o tribunal valorará el alcance del decomiso anterior acordado al resolver sobre el decomiso en el nuevo procedimiento.

5. El decomiso a que se refiere este artículo no será acordado cuando las actividades delictivas de las que provengan los bienes o efectos hubieran prescrito o hubieran sido ya objeto de un proceso penal resuelto por sentencia absolutoria o resolución de sobreseimiento con efectos de cosa juzgada».

113 El Código se extiende en su detallada regulación del decomiso hasta el 127 «sexies». A resaltar la regulación en 127 ter del decomiso sin condena «1.El juez o tribunal podrá acordar el decomiso previsto en los artículos anteriores aunque no medie sentencia de condena, cuando la situación patrimonial ilícita quede acreditada en un proceso contradictorio y se trate de alguno de los siguientes supuestos:

a) Que el sujeto haya fallecido o sufra una enfermedad crónica que impida su enjuiciamiento y exista el riesgo de que puedan prescribir los hechos,

b) se encuentre en rebeldía y ello impida que los hechos puedan ser enjuiciados dentro de un plazo razonable, o

c) no se le imponga pena por estar exento de responsabilidad criminal o por haberse ésta extinguido.

2. El decomiso al que se refiere este artículo solamente podrá dirigirse contra quien haya sido formalmente acusado o contra el imputado con relación al que existan indicios racionales de criminalidad cuando las situaciones a que se refiere el apartado anterior hubieran impedido la continuación del procedimiento penal». 
o la que tiene como sujetos a sus funcionarios. En este contexto la política criminal frente a la corrupción, propugnada por las instituciones internacionales, no se proyecta únicamente sobre el Derecho penal, que no debe perder en ningún caso su carácter fragmentario y de última ratio, sino que tiene que afectar a otras ramas del ordenamiento jurídico y a la política en general.

Los instrumentos internacionales contra la corrupción han llevado al legislador español a la realización de reformas, no siempre acertadas, del Código penal, las más recientes entrarán en vigor el uno de julio de 2015.

Pero, la eficacia de la lucha contra la corrupción y la disminución de sus efectos políticos y sociales están condicionadas especialmente por reformas procesales que hagan más rápida su aplicación y por las políticas de transparencia que ahora parece que comienzan a aplicarse.

TITLE: The International criminal response to corruption. Consequences on the Spanish legislation.

RESUMEN: La corrupción ha adquirido en los últimos años unas magnitudes desorbitadas, por lo que la tradicional politica criminal frente a ella se ha mostrado ineficaz. Este trabajo pretende ofrecer una nueva respuesta frente a la misma teniendo en cuenta su nueva realidad, caracterizada fundamentalmente por su internacionalidad y sus relaciones con otras actividades delictivas como la delincuencia económica, el blanqueo de capitales y el crimen organizado. La nueva respuesta no ha de caer en el error de recurrir al llamado Derecho penal simbólico, sino que debe propugnar políticas mucho más complejas de carácter preventivo, que pasan por la transparencia generalizada y por la utilización de otras ramas del ordenamiento jurídico.

PALABRAS CLAVE: Corrupción, política criminal, código penal, convenio internacional.

ABSTRACT: Corruption has acquired an exorbitant scale in the last years. Due to this fact, the traditional criminal policy against corruption is not effective. This paper offers a new response to combat corruption taking into account its new reality, primarily characterised by the internationality and the relationships with other criminal activities such as economic crime, money laundering and organised crime. The new response should not focus on the so-called symbolic criminal law, but on preventive policies such as the generalised transparency and the use of other branches of the legal system.

KEY WORDS: Corruption, criminal policy, criminal code, international convention. 
